\title{
LOS EMPRESARIOS MEXICANOS DURANTE EL GOBIERNO DE PENAA NIETO ${ }^{1}$
}

\author{
MEXICAN BUSINESS LEADERS DURING THE PEÑA \\ NIETO ADMINISTRATION
}

\section{LES HOMMES D'AFFAIRES MEXICAINS SOUS LE GOUVERNEMENT DE PENAA NIETO}

\author{
Carlos Alba Vega \\ El Colegio de México \\ calba@colmex.mx
}

\begin{abstract}
REsumen: Con base en el examen de hechos cruciales tanto del ámbito económico como electoral, se estudian las relaciones entre el sector empresarial y el Estado mexicano durante el gobierno del presidente Enrique Peña Nieto. Tras un análisis histórico que llega a la actualidad, se profundiza en la relación de los empresarios con los gobiernos del PAN, lo cual a su vez se relaciona directamente con la transición a la democracia en México en el año 2000. El centro del análisis es la relación de los empresarios con el gobierno de Peña Nieto a partir de las reformas más importantes para los empresarios: la fiscal y la energética, sin soslayar la laboral y la educativa. Al final del texto se presenta una caracterización de la relación de los empresarios con Andrés Manuel López Obrador como candidato y como presidente en su primer año de gobierno.

Palabras clave: relaciones empresarios-Estado mexicano; relaciones empresarios-gobiernos del PAN; relaciones empresarios-gobierno de Peña Nieto; relaciones empresarios-Andrés Manuel López Obrador.
\end{abstract}

ABstract: Based on an examination of key facts from both the economic and electoral area, this paper looks at relations between the business sector and the Mexican state during the government of President Enrique Peña Nieto. Beginning with a historical analysis that brings us up to the present day, the relation between business leaders and PAN governments are studied, which in

${ }^{1}$ Agradezco a Olga Arreola su valioso apoyo en la investigación hemerográfica. 
turn is directly linked to the transition to democracy in Mexico in the year 2000. The center of this analysis is the relationship between business leaders and the Peña Nieto government in light of the most significant reform to the business sector: the fiscal and energy reform, without disregarding labor and education reform. The text concludes with a characterization of the relation between the business sector and Andrés Manuel López Obrador, both as a candidate and during his first year in office as president.

Keywords: relations business-Mexican state; relations business-PAN governments; relations business-Peña Nieto; relations businessAndrés Manuel López Obrador.

\section{Traducción de Gonzalo Celorio Morayta}

RÉsumé: À partir de faits importants, d'ordre économique et électoral, nous passons en revue les rapports entre le secteur privé et l'État mexicain sous le gouvernement du président Enrique Peña Nieto. Pour mieux les situer, notre analyse d'histoire contemporaine insiste sur les liens des entrepreneurs avec les gouvernements précédents (ceux du PAN), parmi les éléments qui expliquent la transition démocratique en 2000. Quant au gouvernement de Peña Nieto (notre objet d'étude principal), ses réformes les plus intéressantes pour les hommes d'affaires sont la fiscale et l'énergétique, mais aussi celles qui concernent le travail et l'éducation. Encore dans un but de comparaison, l'article esquisse les relations du secteur privé avec le président successeur, Andrés Manuel López Obrador, le long de sa campagne électorale et de sa première année au pouvoir.

Mots clefs: relations entrepreneurs-État mexicain, relations entrepreneurs-gouvernements du PAN; relations entrepreneursgouvernement de Peña Nieto; relations entrepreneurs-

Andrés Manuel López Obrador.

Traducción de Bernardo Mabire

Fecha de recepción: junio de 2019

Fecha de aceptación: noviembre de 2019 


\section{INTRODUCGIÓN}

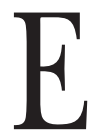

n este texto nos interesa examinar las relaciones entre los empresarios y el Estado en México durante el gobierno del presidente Enrique Peña Nieto a partir de la selección y análisis de algunos hechos cruciales para esa relación, en especial, dos de las llamadas reformas estructurales, la fiscal y la energética, y el proceso electoral, que fue escenario de un enfrentamiento entre el candidato de la coalición Juntos Haremos Historia, Andrés Manuel López Obrador, y algunos de los grandes empresarios, al final del periodo de Peña Nieto. El texto está dividido en cuatro partes; en la primera, para contextualizar el proceso, se presenta de manera sumaria la relación de largo plazo entre empresarios y Estado en México; en la segunda se hace un breve recuento de las singularidades de la relación de los empresarios con los gobiernos del Partido Acción Nacional (PAN), las cuales fueron esenciales para el arribo del primer gobierno de alternancia, encabezado por Vicente Fox, un candidato de origen empresarial que llegó al poder postulado por el PAN. En la tercera se aborda la relación entre los empresarios y el gobierno de Peña Nieto a partir del análisis de la reforma fiscal, a la que los empresarios se opusieron sin éxito, y de la reforma energética, que los más importantes de ellos, junto con las transnacionales, habían esperado y promovido por tanto tiempo. Aunque hubo otras reformas durante el periodo en cuestión, como la laboral y la educativa, nos limitaremos a las dos anteriores por razones de espacio y por considerar que las económicas fueron más relevantes para el empresariado. En la cuarta parte se abordan las relaciones de los empresarios con Andrés Manuel López Obrador, antes, durante su campaña y después de su triunfo electoral. 


\section{LA RELACIÓN DE LARGO PLAZO ENTRE EMPRESARIOS Y Estado en México}

Los empresarios mexicanos empezaron el siglo $\mathrm{xx}$ con un déficit de legitimidad política y a la defensiva debido a la Revolución que, sin negarlos radicalmente como lo hicieron las revoluciones soviética y china, los sacó del escenario sociopolítico varias décadas, y terminaron dicho periodo en la cima del poder económico y político. ${ }^{2}$ Las características del Estado posrevolucionario lo colocaron fuera de las instancias de representación política que sí tuvieron otras categorías sociales, como los campesinos (con la Confederación Nacional Campesina, CNC), los obreros (con la Confederación Revolucionaria de Obreros y Campesinos, CROc; la Confederación de Trabajadores de México, cTM, y la Confederación Regional Obrera Mexicana, CROM) y los sectores populares en las ciudades (con la Confederación Nacional de Organizaciones Populares, CNOP), quienes se hicieron representar de manera directa en las organizaciones de base del partido en el gobierno. ${ }^{3}$ Por invitación gubernamental, los empresarios crearon sus órganos de representación: la Confederación de Cámaras Nacionales de Comercio, Servicios y Turismo (Concanaco), en 1917, y la Confederación de Cámaras Industriales de los Estados Unidos Mexicanos (Concamin), en 1918, así como diversas cámaras sectoriales, como la Cámara Nacional de la Industria de Transformación (Canacintra, en 1941), ${ }^{4}$ a las que debieron afiliarse por obligación desde 1936 hasta 1996. Pero la relación era de naturaleza corporativa y muy pronto sintieron que esos órganos no eran suficientes para defender sus intereses, por lo que crearon otras organizacio-

${ }^{2}$ Roderic Ai Camp, Entrepreneurs and politics in twentieth century Mexico, Nueva York/ Oxford, Oxford University Press, 1989.

3 Julio Labastida (comp.), Grupos económicos y organizaciones empresariales en México, México, Alianza Editorial Mexicana-unam, 1986.

${ }^{4}$ Kenneth C. Shadlen, Democratization Without Representation: The Politics of Small Industry in Mexico, University Park, Pennsylvania, Penn State Press, 2010. 
nes autónomas a lo largo del tiempo. Primero, los empresarios de Monterrey, los más poderosos, independientes y mejor organizados, ${ }^{5}$ crearon la Confederación Patronal de la República Mexicana (Coparmex), ${ }^{6}$ en 1926, sindicato patronal de filiación voluntaria que nació para acoger a empresarios de cualquier actividad económica, dimensión o ubicación geográfica, con el que pudieran defender de manera unificada sus intereses frente a las políticas públicas que sintieron que los lesionaban. Después, en el contexto de la Guerra Fría y del triunfo de la Revolución cubana, y ante una creciente presencia del Estado en la economía, un grupo de empresarios de la Ciudad de México creó el Consejo Mexicano de Hombres de Negocios en 1962 (hoy llamado Consejo Mexicano de Negocios, $\mathrm{CMN}),{ }^{7}$ una organización muy pequeña pero muy poderosa a la que se accede sólo por invitación, la cual al principio constaba de 12 miembros y ahora agrupa a cerca de cincuenta. El Consejo ha tenido una influencia privilegiada con el gobierno y en las políticas públicas.

Durante la etapa del modelo de industrialización por sustitución de importaciones (ISI), o de "desarrollo hacia adentro”, el Estado protegió la industria nacional y brindó diversos estímulos fiscales y precios subsidiados de bienes y servicios a la población y a los empresarios. Cuando el Isi se agotó y el Estado intentó reactivarlo interviniendo en forma creciente

${ }^{5}$ Mario Cerutti, Burguesía y capitalismo en Monterrey, 1850-1910, Monterrey, Claves Latinoamericanas, 1983; Mario Cerutti, Propietarios, empresarios y empresa en el norte de México: Monterrey: de 1848 a la globalización, México, Siglo xxi, 2000; Juan Zapata Novoa, Tercos y triunfadores de Monterrey; los retos de Monterrey en el siglo Xx, Monterrey, Castillo, 1993.

${ }^{6}$ Jorge Buendía Laredo, "Autoritarismo y participación empresarial: La Confederación Patronal de la República Mexicana, 1970-1988”, tesis de licenciatura en Relaciones Internacionales, Centro de Estudios Internacionales, El Colegio de México, 1989.

7 Alicia Ortiz Rivera, "Consejo Mexicano de Hombres de Negocios: ¿Poder tras la silla presidencial?”, tesis de maestría en Sociología Política, México, Instituto Dr. José María Luis Mora, 1998; Marcela Briz Garizurieta, El Consejo Mexicano de Hombres de Negocios, surgimiento y consolidación, México, unam, 2002. 
en la economía como productor, distribuidor y regulador, el CMN creó como respuesta política el Consejo Coordinador Empresarial (CCE, en 1976) para agrupar en una cúpula los intereses de los diversos sectores de actividad económica dispersos en cámaras y asociaciones empresariales (Concanaco, Concamin, CMN, Coparmex, Consejo Nacional Agropecuario, Asociación Mexicana de Instituciones de Seguros, Asociación de Bancos de México). El caE se creó, según lo establece en su página web, "como una respuesta del sector productivo nacional a la creciente intervención del gobierno en la economía y la aplicación de medidas claramente populistas". ${ }^{8} \mathrm{Al}$ sobrevenir la crisis de la deuda de 1982 y cuando el gobierno de López Portillo expropió la banca, muchos empresarios pequeños y medianos que se politizaron en los centros empresariales de la Coparmex y en algunas de las cámaras, decidieron participar directamente en o con los partidos, en algunos casos respaldados por los grandes empresarios, para influir en las políticas públicas. ${ }^{9}$ Se presentaron en el escenario público con una legitimidad que habían perdido los políticos tradicionales. Primero lo hicieron en la corriente neopanista y después también con el Partido Revolucionario Institucional (PRI). Asimismo, aunque en mucho menor medida, en el Partido de la Revolución Democrática (PRD). Desde el PAN y el PRI conquistaron alcaldías, diputaciones y gubernaturas en los espacios más modernizados y alejados del poder central, sobre todo en el norte de México, hasta que el PAN logró, con un empresario, la primera alternancia política nacional en 2000. Paralelamente y en convergencia con muchos de los intereses de los empresarios politizados, arribó al poder una nueva elite tecnocrática que impulsó un cambio de rumbo en el modelo económico desarrollista y nacionalista, para lo

${ }^{8}$ Consejo Coordinador Empresarial, CCE, "Historia" CCE, https:// www.cce.org.mx/historia/

${ }^{9}$ Ricardo Tirado y Matilde Luna, "La politización de los empresarios mexicanos (1970-1982)", en Julio Labastida: Grupos económicos y organizaciones empresariales en México, México, Alianza Editorial Mexicana-unam, 1986, pp. 411-455. 
que se propuso redimensionar el Estado, así como liberalizar y orientar hacia afuera la economía, convirtiendo a los grandes empresarios mexicanos y a la inversión extranjera en los agentes centrales del desarrollo. Eso supuso una serie de transformaciones: la reprivatización de los bancos y la privatización de las empresas paraestatales, muchas de las cuales fueron adquiridas por miembros del $\mathrm{CmN} ;{ }^{10}$ la desregulación económica, incluida la Ley de Inversión Extranjera, en la que participaron también miembros destacados del CMN, y la apertura comercial, con la adhesión de México, en 1986, al Acuerdo General sobre Aranceles Aduaneros y Comercio, (GATT, por sus siglas en inglés, que después daría lugar a la Organización Mundial del Comercio, OMC), la incorporación, en 1994, a la Organización para la Cooperación y el Desarrollo Económicos (OCDE) y la firma del Tratado de Libre Comercio de América del Norte (TLCAN), procesos en los que algunos de los grandes empresarios participaron como asesores a través de la Coordinadora de Organizaciones Empresariales de Comercio Exterior (COECE) en el "cuarto de junto".

La caída del mercado interno, el incremento de la competencia y la globalización llevaron a los pequeños empresarios a replegarse, a cambiar de actividad y en muchos casos a desaparecer, mientras que los grandes empresarios tuvieron incentivos para incursionar en el mercado exterior y desde los años noventa se transnacionalizaron e hicieron inversiones productivas, primero en América Latina y Estados Unidos, después en Europa, el norte de África y el Medio Oriente y, finalmente, en Asia. Esa emisión de capitales de México hacia el exterior en algunos años ha sido tan importante como la llegada de inversión extranjera.

Las organizaciones empresariales también se han transformado. La apertura económica y el incremento de la inversión extranjera, las crisis económicas (1982, 1994, 2001, 2008), la

${ }^{10}$ Elvira Concheiro, El gran acuerdo. Gobierno y empresarios en la modernización salinista, México, Instituto de Investigaciones Económicas, UNAM / Era, 1996. 
división de poderes propia de la democracia y la falta de políticas industriales se reflejaron en el debilitamiento de las organizaciones industriales, mientras que el CCE ha logrado mantener la representación del conjunto del empresariado y sigue siendo el principal interlocutor ante el gobierno. El CMN, la más poderosa organización de los empresarios, ha ganado visibilidad pública, pero ha perdido poder; abrió sus puertas por primera vez a la participación de las mujeres y ha habido un cambio generacional en su seno, pero han surgido nuevos actores y organizaciones con los que debe compartir la interlocución con el gobierno. Entre ellos, destaca el Consejo Ejecutivo de Empresas Globales (CEEG), constituido por 51 grandes empresas transnacionales que son responsables de 500000 empleos directos, de los cuales más de 10000 requieren personas con posgrado; además, las empresas del CEEG tienen el $20 \%$ de sus puestos directivos ocupados por mujeres, contra $13.5 \%$ de las 500 empresas más grandes de México. Este consejo no solamente ha abierto la puerta a las mujeres, sino que una de ellas lo preside desde 2019.

A pesar de la afinidad de gran parte de los empresarios con el PAN, cuando éste llegó a la presidencia no logró realizar las reformas más buscadas por ellos, lo que se debió a que por primera vez el gobierno estuvo dividido y el presidente no tenía mayoría en el Congreso. Por lo tanto, los vínculos privilegiados de los empresarios, especialmente el CMN, con el poder ejecutivo fueron insuficientes para promover sus intereses; así, surgió la necesidad crear por primera vez en las grandes empresas y en las organizaciones empresariales órganos de vinculación y cabildeo con el poder legislativo.

Además de los cambios en el campo económico, desde los años noventa y, sobre todo, durante las administraciones panistas, los empresarios, las organizaciones civiles, el gobierno, las instituciones académicas y las organizaciones sociales y laborales, emprendieron acciones y crearon instancias de concertación desde la sociedad civil para promover de manera muy activa diversas causas: ampliación de la democracia, fortalecimiento de la seguridad y abatimiento de la 
violencia, calidad de la educación, transparencia y rendición de cuentas, lucha contra la corrupción y la impunidad, promoción de la inclusión y el desarrollo local. Varias de estas organizaciones sirven de contrapeso al poder económico o al gubernamental, y son útiles para brindar información oportuna y vigilar críticamente las políticas públicas, así como para crear consensos que ayuden a encarar, debatir y resolver problemas de orden colectivo.

Con estas acciones políticas, económicas y sociales, los empresarios se colocaron simultáneamente en las esferas del Estado, del mercado y de la sociedad civil, entrelazamiento que genera tensiones entre los intereses privados y públicos, como se expresó en los casos de Amigos de Fox, la Ley Televisa y la injerencia del CCE en la sucesión presidencial de 2006. Esta integración económica, política y social llama a la necesidad de regular y establecer fronteras claras entre las tres esferas. ${ }^{11}$

El activismo de los empresarios contrasta con el apocamiento de las organizaciones de trabajadores, cuyos líderes, en el marco de las crisis, de las reestructuraciones productivas y del nuevo modelo de industrialización volcado hacia afuera, ya no tuvieron la capacidad de conseguir salarios y empleos, que eran la fuente de su legitimidad, ni las relaciones y los apoyos internacionales que habían obtenido, por lo que también el corporativismo entró en crisis. ${ }^{12}$ Por ejemplo, la American Federation of Labor and Congress of Industrial Organizations (AFL-CIO), que apoyó a las organizaciones laborales de México durante las negociaciones del TLCAN, no lo hizo ya en el caso del Tratado entre México, Estados Unidos y Canadá (T-MEC).

${ }^{11}$ Matilde Luna, "Las asociaciones empresariales y el Estado panista", en Enrique de la Garza Toledo (coord.), La situación del trabajo en México, 2012. El trabajo en la crisis, México, Plaza y Valdés Editores, 2012, p. 690.

${ }^{12}$ Sobre el corporativismo mexicano puede consultarse el trabajo de Ilán Bizberg, "Auge y decadencia del corporativismo", en Ilán Bizberg y Lorenzo Meyer (coords.), Una historia contemporánea de México: transformaciones y permanencias, México, Océano, 2003, pp. 313-366. 
El modo de inserción de México en la economía internacional y su acentuada sincronización y dependencia de Estados Unidos llevaron a que fuera uno de los países más afectados por la crisis de 2008. Desde la crisis de 1982 y hasta 2018, ni los gobiernos priistas ni los panistas concibieron un proyecto de país que orientara el desarrollo priorizando el mercado interno, lo que lo hizo más vulnerable a las crisis y choques externos y no mejoró los indicadores laborales. Si se toma como referente el mercado de trabajo, los primeros 17 años del siglo XXI no manifiestan un panorama optimista en cuanto al empleo. ${ }^{13}$ Por el contrario, se percibe un deterioro diferenciado por edades, en el que los jóvenes resultan ser los más afectados, además de que la brecha entre las condiciones laborales de las mujeres y las de los hombres se mantiene y si disminuye es debido al deterioro de las condiciones de los hombres. Por otra parte, la tendencia a que las mujeres se incorporen al mercado de trabajo se ha frenado en los últimos años. Asimismo, las condiciones de quienes trabajan en la economía informal y las de los empleados de pequeñas empresas se han aproximado a las de sus patrones, pero el acercamiento es por el deterioro de las circunstancias de estos últimos. Tampoco se perciben avances notables en los niveles de ingresos, en el acceso a la seguridad social y en el tipo de contratación. Los ingresos de quienes laboran en condiciones de formalidad e informalidad se han aproximado desde la recesión de 2008 por el mayor declive en las percepciones de los primeros; lo mismo ocurre con los trabajadores más escolarizados respecto a los de menor preparación. También se mantienen las distancias entre los niveles de bienestar de la población que habita en las entidades federativas del sur (más bajos) respecto de los del norte. Por lo tanto, el trabajo de los mexicanos se ha precarizado en forma diferenciada a

13 Carlos Alba Vega y Mauricio Rodríguez, "Trabajo y desigualdad. La precarización del trabajo y de los salarios de 2000 a 2017", en Melina Altamirano y Laura Flamand (coords.), Desigualdades en México 2018, México, El Colegio de México (en prensa). 
principios del siglo XxI y es perceptible una tendencia a la igualación por empobrecimiento. Después de presentar este panorama sumario y general conviene abordar el momento de los empresarios durante los gobiernos del PAN.

\section{LOS EMPRESARIOS DURANTE LOS GOBIERNOS DEL PAN}

El triunfo del PAN en las elecciones presidenciales de 2000 abrió la alternancia política en México después de 70 años de control priista; sin duda, los empresarios tuvieron mucho que ver con este cambio. ${ }^{14}$ Desde la crisis de la deuda y la expropiación bancaria de $1982,{ }^{15}$ muchos se habían politizado en los organismos empresariales, en especial en la Coparmex, de diversas regiones del norte ${ }^{16}$ y noroeste del país, ${ }^{17}$ en las zonas más modernizadas y menos dependientes del modelo de sustitución de importaciones, que se caracterizó por la protección de la industria nacional de la competencia externa. De hecho, Vicente Fox llegó a la presidencia de la República como un candidato de origen empresarial, sin embargo, a diferencia de los gobiernos anteriores, ya no tuvo el control del Congreso porque éste se hallaba dividido desde que el PRI perdiera la mayoría, en 1997. Este cambio de los empresarios hacia la acción política partidaria se empalmó con otra mudanza: la reorganización de sus empresas, que

${ }^{14}$ Matilde Luna, "Los empresarios en el proceso de cambio político", Metapolítica (2007), núm. 54, pp. 72-78.

${ }^{15}$ Carlos Elizondo, "The making of a new alliance: the privatization of the banks in Mexico", documento de trabajo, Estudios Políticos, México, Centro de Investigación y Docencia Económicas, 1993.

${ }^{16}$ Alberto Aziz Nassif, Chihuahua: historia de una alternativa, La Jornada / CIEsAs, 1994; Yemile Mizrahi, "La nueva oposición conservadora en México: la radicalización política de los empresarios norteños", Foro Internacional, 32 (1992), pp. 744-771; Rocío Guadarrama Olivera, Los empresarios norteños en la sociedad y la política del México moderno. Sonora /1929-1988, México, El Colegio de México / El Colegio de Sonora / UAM, 2001.

${ }^{17}$ Hubert Carton de Grammont, Los empresarios agrícolas y el Estado. Sinaloa, 1893-1984, México, IIS-UnAM, 1990. 
debieron reestructurarse debido a la crisis y la apertura del mercado y, por lo tanto, a la presión de la competencia.

Matilde Luna ha examinado las características de las relaciones entre los empresarios y los gobiernos panistas. ${ }^{18}$ Una de sus ideas centrales es que a pesar de la presumible afinidad entre los empresarios y el PAN, que llevó a la presidencia a Fox, la relación entre ellos en los dos sexenios ha sido difícil y ha influido negativamente en la fortaleza de las instituciones políticas y en la capacidad de los actores para llegar a acuerdos en un entorno económico, social y político nacional e internacional mucho más complejo, derivado de la incipiente transición democrática, de la creciente internacionalización de la economía mexicana y de la crisis global de 2008.

El origen panista del gobierno no parece haber cambiado las formas de participación política de los empresarios. Su acción y sus asociaciones durante los dos sexenios del PAN revelarían un problema más antiguo y de más fondo, relacionado con la falta de normas que al mismo tiempo fortalezcan la autonomía del sistema económico, regido por la competencia, regulen las nuevas interdependencias entre la economía y la política, y normen la relación entre la economía nacional y el mercado internacional, ahora como campo prioritario de los grandes empresarios exportadores con inversiones económicas, también, en otros países.

Además, para Matilde Luna y Marcela Briz Garizurieta, ${ }^{19}$ varias de las grandes organizaciones empresariales han perdido fuerza en las dos últimas décadas como consecuencia de los cambios en el sistema político y de la internacionalización de la economía mexicana, aunque no es el caso del CCE, pero sí del CMN, la Concamin ${ }^{20}$ y la Canacintra; y en el esce-

${ }^{18}$ M. Luna, "Las asociaciones empresariales...", op. cit.

19 Marcela Briz Garizurieta, "El Consejo Mexicano de Hombres de Negocios en la transición hacia un nuevo modelo de desarrollo", tesis de doctorado en Ciencias Políticas y Sociales, unAm, 2006.

${ }^{20}$ Carlos Arriola, "La Concamin”, en Carlos Alba Vega (coord.), Historia y desarrollo industrial de México, México, Concamin, 1988, pp. 233-275; Ricardo Tirado, "El poder en la Confederación de Cámaras Industriales", 
nario han aparecido otros actores, algunos individuales y otros en forma de acción colectiva. Entre las nuevas organizaciones empresariales se destaca el CEEG, creado en 2004, el cual reúne a los presidentes y directores generales de 51 empresas multinacionales con operaciones en México. ${ }^{21}$ Según sus propias declaraciones, representan el $10 \%$ del producto interno bruto (PIB), el $40 \%$ de la inversión extranjera y el $11 \%$ de las exportaciones mexicanas. Todas son empresas públicas que cotizan en la bolsa. Sus integrantes pretenden "construir un diálogo continuo con el gobierno, organismos empresariales, sociedad civil, líderes de opinión y académicos para buscar soluciones para hacer de México un país más competitivo, más productivo y equitativo". Entre sus objetivos declarados están los de promover un mejor entorno de negocios y fomentar la competitividad de México; atraer inversión extranjera y generar incentivos para el crecimiento económico sostenido y equitativo para alcanzar mayores niveles de inclusión social y sustentabilidad. ${ }^{22}$ El CEEG generó un proyecto denominado "México 2030 ante la cuarta revolución industrial. Propuestas para la productividad, el crecimiento y la inclusión social", ${ }^{23}$

en C. Puga y M. Luna (coords.), Acción colectiva y organización. Estudios sobre desempeño asociativo, México, IIs-UnAM, 2008, pp. 93-142.

${ }^{21}$ Las empresas del Consejo Ejecutivo de Empresas Globales son: Авв, Airbus, Air Liquid, American Express, Arcelor Mittal, AT\&т, AXXA, BASF, Bayern, Bosch, Brookfield, BP, Cargill, Caterpillar, Citi Banamex, CocaCola México, Daimler, Danone, DHL, Du Pont, ExxonMobil, Fiat Chrysler Automobiles, FedEx, General Electric Imagination of Work, General Motors, Holcim, Honeywell, HsBC, Iberdrola, Johnson Controls, Kansas City Southern de México, Laureate International Universities, Manpower. MetLife, Microsoft. Nestlé, PepsiCo, Philips, Posco, Prologis, Schindler, Schneider Electric, Scotiabank, Seguros Monterrey, Shell, Siemens, Telefónica, Thales, Toyota y Visa. "Nuestros socios", Consejo Ejecutivo de Empresas Globales, CEEG, http://ceeg.mx/

22 "Mensaje de Claudia Jañez", México, CEEG, http:/ / ceeg.mx/ mensaje-de-claudia-janez/ (consulta del 28 de junio de 2019); Consejo Ejecutivo de Empresas Globales, CEEG, "El CEEG en cifras", http:/ / ceeg.mx/ (consulta del 28 de junio de 2019).

${ }^{23}$ Consejo Ejecutivo de Empresas Globales, CEEG, México 2030 ante la cuarta revolución industrial. Propuestas para la productividad, el crecimiento y la inclusión social, México, 2016. 
el cual puede consultarse en línea. En la campaña presidencial de 2018, el CEEG se reunió con los candidatos de la coalición Todos por México, José Antonio Meade ( 7 de mayo de 2018), ${ }^{24}$ y de la coalición Juntos Haremos Historia, Andrés Manuel López Obrador (24 de abril de 2018). ${ }^{25}$

La llegada del PAN a la presidencia de la República en 2000 produjo una más clara división real de poderes, en especial entre el ejecutivo y el legislativo, y ya que en 1997 el PRI había perdido la mayoría en el Congreso, para los empresarios ya no fue suficiente acordar con el ejecutivo; las organizaciones empresariales y las grandes empresas debieron desplegar estrategias para relacionarse también con el poder legislativo, para lo cual crearon instancias de cabildeo. ${ }^{26}$ Sin embargo, como lo ha advertido Matilde Luna, la expansión y la creciente autonomía del poder legislativo debilitó el poder de las grandes organizaciones empresariales, al disminuir su capacidad de negociación directa con el presidente y sus secretarios y de éstos con el Congreso; y mermó también la influencia de las organizaciones que agrupan a los pequeños empresarios, ya que la obligación, que existía desde 1936, de estar asociado a una cámara terminó en $1996,{ }^{27}$ y éstas perdieron muchos afiliados, debieron reestructurarse y algunas hasta subarrendaron parte de sus inmuebles.

Por otra parte, durante los gobiernos panistas continuó y se aceleró el acercamiento, la identidad y la visibilidad que se venían dando desde los años ochenta entre los poderes político y económico. Esta proximidad se expresó en varios ámbitos.

En primer lugar, el desarrollo de los partidos políticos y de la competencia electoral ofreció a los empresarios la oportuni-

${ }^{24}$ Sesión con el Dr. José Antonio Meade, candidato de la coalición Todos por México, Ciudad de México, 7 de mayo de 2018.

${ }^{25}$ Sesión con el Lic. Andrés Manuel López Obrador, candidato de la Coalición Juntos Haremos Historia, Ciudad de México, 24 de abril de 2018.

${ }^{26}$ Carlos Alba Vega, "Los empresarios y la democracia en México", Foro Internacional, 96-1 (2006), pp. 122-149.

27 Carlos Arriola, "La Ley de Cámaras Empresariales y sus Confederaciones", Foro Internacional, 37 (1997), pp. 634-660. 
dad de representar sus intereses como candidatos en todos los partidos, en especial en el PRI y en el PAN, y de participar en todos los cargos gubernamentales, tanto los de elección (alcaldías, diputaciones locales y federales, senadurías, gubernaturas) como en los de designación (secretarios de Estado y otros cargos federales, estatales y municipales, especialmente los vinculados con temas económicos). Varios de los secretarios iniciales de Fox no provenían de la militancia panista, como se esperaba en el partido, sino del sector empresarial; además, no necesariamente contaban con saber técnico (aunque hubo excepciones), ni con experiencia política, pero sí con intereses personales en su área de actividad. Fueron los casos del secretario de Agricultura, que era un gran productor y exportador agrícola; el de Energía, que había sido director de grandes empresas nacionales y extranjeras; el de Comunicaciones y Transportes, que había sido un alto directivo de Teléfonos de México, y el del Trabajo, que había sido presidente de la Coparmex, el más importante sindicato patronal. ${ }^{28}$

En segundo lugar, el acercamiento entre los ámbitos económico y político se manifestó en la irrupción de empresarios y organizaciones empresariales en diversos ámbitos de la sociedad civil, en defensa de múltiples causas económicas, sociales, políticas y culturales: desde la búsqueda de la ampliación de la democracia y la lucha por la seguridad, la justicia y el mejoramiento de la educación, hasta el combate contra la corrupción y la impunidad. Esta llegada de los empresarios a la sociedad civil creció progresivamente. Algunos ejemplos de estas instituciones son Integra (1983), el Centro Mexicano para la Filantropía (Cemefi, 1988), el Fideicomiso Fondo Social del Empresariado Chihuahuense (Fechac, 1994), México Unido contra la Delincuencia (1998), el Instituto Mexicano para la Competitividad (IMco, 2003), Fundación del Empresariado en México (Fundemex, 2004), Mexicanos Primero (2006), Causa en Común (2010), Fundación Coparmex (2012) y Mexicanos contra la Corrupción y la Impunidad

${ }^{28}$ M. Luna, "Las asociaciones empresariales...”, op. cit. p. 670. 
(2015). En 2016, por primera ocasión, los empresarios agrupados en la Coparmex se manifestaron en el Ángel de la Independencia en contra de los corruptos y la impunidad, ocasión en la que Gustavo de Hoyos, presidente de la Confederación, dirigió un mensaje en contra del contenido de la ley aprobada por los senadores, Ley General de Responsabilidades Administrativas (conocida como 3 de 3). En ese evento señaló que "la sociedad cada vez juega un papel más activo" y "la aprobación del Sistema Nacional Anticorrupción es un triunfo de la sociedad mexicana". ${ }^{29}$

Otras formas de entrelazamiento de los poderes económico y político a través del desarrollo de organizaciones civiles se expresaron con un respaldo poco transparente de algunos empresarios y partidos políticos, como el PAN y el Partido Verde Ecologista de México (PVEM), que financiaron campañas y causas sociales. Dos de estas asociaciones civiles fueron Amigos de Fox, que financió su campaña como candidato, y la Fundación Vamos México, de Martha Sahagún, esposa de ese presidente panista, orientada a obras altruistas. En contraste con otras organizaciones filantrópicas que estaban en penuria por falta de apoyos económicos, esta última recibía generosas donaciones, públicas y privadas, en cantidades incuantificables, con origen y destino poco claros y sin ningún control. ${ }^{30}$

Otro tipo de organismos civiles surgieron de los empresarios y las organizaciones empresariales. Un caso notable fue el del Acuerdo Nacional para la Unidad, el Estado de Derecho, el Desarrollo, la Inversión y el Empleo, mejor conocido como el Acuerdo de Chapultepec, firmado el 29 septiembre de $2005,{ }^{31}$ con el empresario Carlos Slim a la cabeza, y presen-

29 "No más corruptos impunes: empresarios de la Coparmex se manifiestan en el Ángel", Animal Político, 16 de junio de 2016, https://www. animalpolitico.com/2016/06/no-mas-corruptos-impunes-empresariosse-manifiestan-en-el-angel-por-leyes-anticorrupcion/

30 "Vamos México, sin control", Proceso, 25 de mayo de 2003.

31 "Acuerdo Nacional para la Unidad, el Estado de Derecho, el Desarrollo, la Inversión y el Empleo”, Acuerdo de Chapultepec, México, 29 de septiembre de 2005, https:/ / www.acuerdodechapultepec.org 
tado como un acuerdo nacional de las organizaciones de la sociedad civil para hacer frente a una previsible crisis política derivada de la fuerte competencia electoral en las elecciones presidenciales de 2006.

Otra clase de organizaciones de la sociedad civil están encauzadas a promover acciones de filantropía a través de fundaciones, muchas de las cuales aparecieron en décadas recientes. Entre estas fundaciones pueden distinguirse las corporativas, muchas de ellas influidas por empresas extranjeras y fundaciones estadounidenses, y las familiares, de raigambre nacional y generalmente más antiguas. Ambas han aprovechado la legislación fiscal que les permite deducir impuestos si los invierten en obras sociales y culturales sin fines de lucro. La mayor parte de las fundaciones altruistas son de corte asistencial y muy pocas de naturaleza transformacional, entendidas estas últimas como las que buscan la autonomía y la independencia económica de los sujetos a los que apoyan.

Otras fundaciones buscan suscitar la responsabilidad social empresarial y otras más se orientan a generar crítica, retroalimentación, diseño de leyes y normas, estudios y seguimiento de determinadas acciones políticas y gubernamentales. También hay algunas orientadas a enfrentar problemas altamente sensibles para la sociedad, como la inseguridad y la violencia, lo que se hizo más evidente durante el sexenio de Felipe Calderón, cuando nació el Instituto Ciudadano de Estudios sobre la Inseguridad, creado en 2006 por el CCE, la Coparmex, la Fundación Este País, la Universidad Nacional Autónoma de México (UnAm) y el Instituto Tecnológico y de Estudios Superiores de Monterrey (ITESM). Otras fundaciones promueven actitudes positivas y valores en la ciudadanía. Un caso más, durante el sexenio de Peña Nieto, fue la creación de Mexicanos contra la Corrupción y la Impunidad.

Desde la última década del siglo xx, a raíz de la caída del mercado interno y de la apertura económica que culminó en la firma de diversos tratados comerciales, entre los que desta- 
can el TLCAN ${ }^{32}$ y el Tratado de Libre Comercio México-Unión Europea (TLCUEM), ${ }^{33}$ se hizo evidente la incursión de los grandes empresarios mexicanos en el ámbito transnacional, tanto como exportadores e inversionistas en otros países, como a través de su participación en organismos creados para influir en las políticas públicas.

Existe un grupo de grandes empresas que se ha transnacionalizado, ${ }^{34} \sin$ embargo, no es posible abordar en este espacio las razones de su salida al exterior, los factores que llevan a las empresas a internacionalizarse, quiénes y cómo se toman las decisiones, cuáles son sus éxitos y sus fracasos. Marcela Hernández ha mostrado que las empresas se han internacionalizado a través de la expansión, por compra parcial y después mayoritaria o total de empresas extranjeras, con lo que pasaron de socios a directivos, o por la creación de nuevas empresas, aumentando el número de subsidiarias en los países de operación. Para iniciar el proceso de internacionalización, fueron importantes las alianzas estratégicas en la producción, mientras que después lo fueron para la comercialización y distribución de los productos. ${ }^{35}$ Por los trabajos de Basave Kunhardt y Gutiérrez Haces sabemos qué empresas salen al extranjero y a qué países, cuáles son los sectores de actividad y los montos de capital. ${ }^{36}$

32 Cristina Puga, Los empresarios organizados y el Tratado de Libre Comercio de América del Norte, México, Facultad de Ciencias Políticas, unAm / Miguel Ángel Porrúa, 2004.

33 Alvaro Castro Espinosa, "Tan lejos de Europa y tan cerca de los Estados Unidos: orígenes, negociación y perspectivas del acuerdo político y comercial entre México y la Unión Europea”, Foro Internacional, 43 (2003), pp. 893-916.

${ }^{34}$ María de los Ángeles Pozas, Estrategia internacional de la gran empresa mexicana en la década de los noventa, México, El Colegio de México, Centro de Estudios Sociológicos, 2002.

35 Marcela Hernández, "Reestructuración del empresariado y de las grandes corporaciones", en Enrique de la Garza (ed.), La situación del trabajo en México: el trabajo en la crisis, México, UAm / Plaza y Valdés, 2012, pp. 697-730.

36 Jorge Basave Kunhardt y María Teresa Gutiérrez-Haces, "Localización geográfica y sectores de inversión: factores decisivos en el desempe- 
Si tomamos las veinte mayores empresas transnacionales mexicanas (véase cuadro 1), podremos observar que los principales activos se concentran en telecomunicaciones, minerales no metálicos y minas, bebidas y alimentos, seguidos de petróleo y gas, química y petroquímica, acero y productos metálicos. Finalmente, están las empresas con activos en medicamentos, construcción, comercio y partes automotrices. El mayor número de filiales, en orden decreciente, se localiza en América Latina y el Caribe, en América del Norte (donde destaca Estados Unidos), en Europa, Asia Oriental y el Pacífico, y finalmente en Oriente Medio y el norte de África.

También se ha investigado sobre la posición del gobierno mexicano ante la transnacionalización de los empresarios, y se ha mostrado que aquél no tiene una estrategia de fomento a la emisión de inversión extranjera directa y de promoción de la internacionalización de las empresas mexicanas, al contrario de lo que ocurre en algunos países emergentes, como Brasil y China. ${ }^{37}$

En cuanto a los organismos creados para incidir en las políticas públicas, dos de los más destacados son el Consejo Mexicano para Asuntos Internacionales (Comexi) y el Instituto Mexicano para la Competitividad (IMCO). El Comexi nació en noviembre de 2001, según su autodefinición, como un foro plural y multidisciplinario, independiente del gobierno, que se financia con aportaciones de sus miembros y está orientado al debate y al análisis del papel de México en el mundo, y a la creciente influencia de los acontecimientos internacionales en el quehacer nacional. Esta organización está asociada a personalidades e instituciones públicas y privadas de diferentes sectores y corrientes ideológicas.

ño de las multinacionales mexicanas durante la crisis", Journal of Economics, Finance and Administrative Science (2013), núm. 34, pp. 34-44.

${ }^{37}$ Francisco Horneffer Rodríguez, "El Estado y la inversión extranjera directa de las empresas mexicanas", tesis de licenciatura en Relaciones Internacionales, El Colegio de México, Centro de Estudios Internacionales, 2012. 


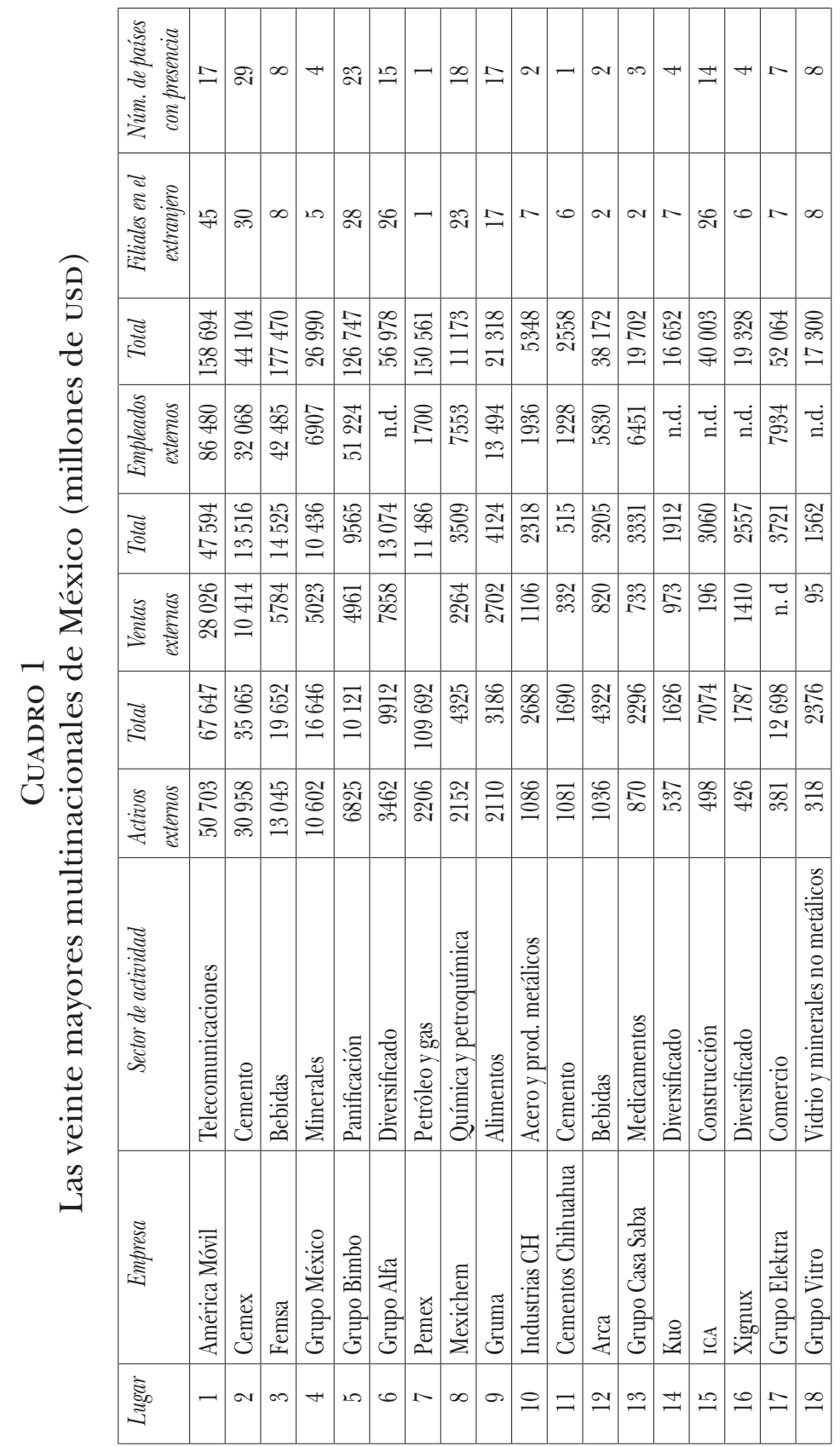




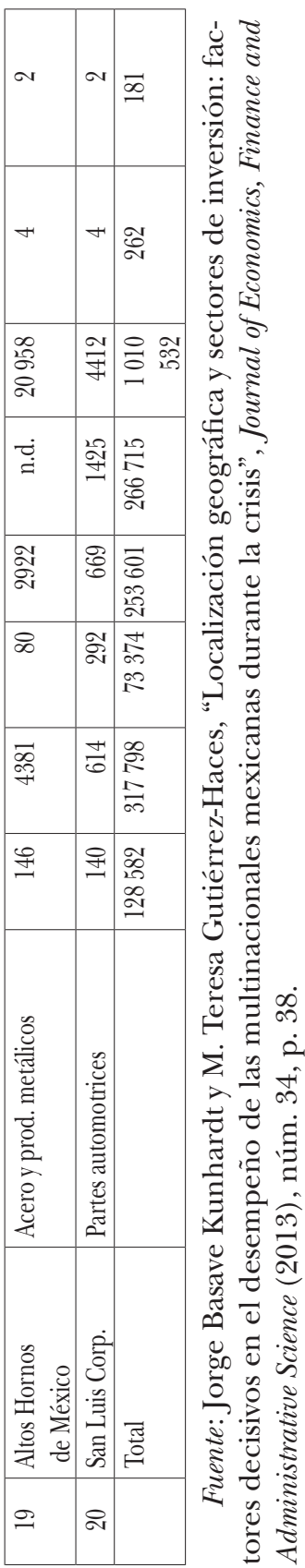


El ImCO, a su vez, es uno de los think tanks del sector privado más influyentes del país. Surgió en 2003, con el apoyo del CMN como donante fundador. Se financia, además de con sus estudios, con el apoyo de diversas empresas e instituciones nacionales e internacionales. Según su autodefinición, es "un centro de investigación aplicada, que es independiente, apartidista y sin fines de lucro. Está orientado al estudio de los fenómenos económicos [...] y a generar propuestas de políticas públicas [...]; por lo tanto, busca influir en su ejecución para fortalecer la competitividad y lograr un México próspero e incluyente". ${ }^{38}$ Sus principales áreas de interés son la transparencia y la rendición de cuentas, la eficiencia en el uso de los recursos públicos, el establecimiento de un Estado de derecho, la seguridad, la sustentabilidad ambiental, la inclusión social, la educación de calidad, el desarrollo de mercados eficientes, la integración de sectores de innovación, la política exterior y México frente a la globalización, el desarrollo urbano y la competitividad de las ciudades, y el impulso de tecnologías de la información y la comunicación. ${ }^{39}$

La reinserción de México en la economía mundial ha propiciado también la colaboración de empresarios, políticos e intelectuales en órganos que buscan participar en la gobernanza global, como la International Commission of Peace and Prosperity, conocida comúnmente como Comisión Trilateral, una organización internacional privada fundada en 1972 por iniciativa de David Rockefeller. ${ }^{40}$

${ }^{38}$ Instituto Mexicano para la Competitividad, AC, https://imco. org.mx

${ }^{39}$ Carlos Alba Vega, "Policy analysis and public policy in the private sector", en José Luis Méndez y Mauricio I. Dussauge-Laguna (eds.), Policy Analysis in Mexico, International Library of Policy Analysis 9, Bristol, Reino Unido / Chicago, Ee.uU., Bristol University Press, 2017, pp. 223-238.

${ }^{40}$ En 2002, participaban por parte de México las siguientes personas: Herminio Blanco Mendoza, exsecretario de Comercio y Fomento Industrial; Dionisio Garza Medina, de Grupo Alfa; Alejandro Junco de la Vega, de Grupo Reforma; Enrique Krauze, de Editorial Clío Libros y Videos; Antonio Madero, de San Luis Corporación; Luis Rubio, de CIDAC; Jaime Serra, de SAI Derecho y Economía, y exsecretario de Comercio y Fomento 
Los empresarios siempre han tenido un papel activo en la vida política del país y en las elecciones, aunque de diferente manera a través del tiempo. Cuando hubo un partido hegemónico, expresaban sus deseos o inconformidades ante ciertas políticas públicas con pronunciamientos en la prensa o en reuniones privadas con el candidato priista o el presidente. Incluso, se estableció la costumbre de que los precandidatos del PRI se reunieran con los miembros del CMN en una famosa pasarela, para explicarles sus planes y proyectos de país, y así los empresarios pudieran expresar su opinión y, llegado el caso, mostrar sus apoyos y reservas sobre cada uno. Sin embargo, desde que la competencia real entre partidos se intensificó y apareció la alternancia, y sobre todo desde que López Obrador se presentó como candidato de izquierda, la participación de los empresarios y sus organizaciones se vigorizó y fue más allá de las mesas de análisis o de ofrecer plataformas para el debate de los candidatos.

Aunque las leyes acotan ahora la discrecionalidad de los empresarios y otros actores en el uso del dinero y del tiempo en los medios, en algunas campañas se han extralimitado, sobre todo en las elecciones de $2006,{ }^{41}$ con despliegues mediáticos a través de spots en radio y televisión tratando de inducir el voto y advirtiendo que "apostar a algo distinto era retroceder". El CCE intervino a través del Consejo de la Comunicación (CC) con dos spots, uno sobre seguridad y otro sobre desempleo, cuyo contenido estaba dirigido a influir en un cambio de preferencias de los votantes. El tema del empleo

Industrial; Luis Téllez, de DESc, y exsecretario de Energía; Lorenzo H. Zambrano, de Cemex, y presidente para América del Norte de la Comisión Trilateral; Ernesto Zedillo, del Yale Center for the Study of Globalization, y expresidente de México. "Lista completa de los miembros de la Comision Trilateral (febrero de 2003)", Solidaridad.net, 28 de marzo de 2003, https://solidaridad.net/lista-completa-de-los-miembros-de-la-comision-trilateral-febrero-de-2003-248/ (consulta del 30 de junio de 2019).

${ }^{41}$ José Muñoz Cota Callejas, "El Consejo Coordinador Empresarial en el sexenio de Vicente Fox", tesis de maestría en Ciencia Política, El Colegio de México, 20 de agosto de 2009. 
era promovido por el candidato del PAN, Felipe Calderón, cuya imagen era invocada como "el presidente del empleo". Con el tema de la inseguridad se mostraba una situación extrema y se basaba sobre todo en las críticas a la Ciudad de México. En los dos anuncios se recurría a temas que causaban miedo e incertidumbre en la población, como "crisis económica", "devaluación" y "desempleo". Parecía claro que se buscaba descalificar a López Obrador y respaldar a Calderón. Además, el presidente Fox intervino de manera directa y permanente contra López Obrador sin nombrarlo, sino utilizando como leitmotivel calificativo de "populista”. Según Georgina Sosa, "hubo entonces una convergencia en los "intereses compartidos' entre Fox y el cCE (que ya tenía su historia durante el sexenio en que aquél gobernó) con esta 'estrategia entrelazada' para atacar al candidato de las izquierdas". ${ }^{42}$

A pesar del origen empresarial de Fox como exalto dirigente de la Coca Cola, y de sus declaraciones, los empresarios no lograron algunos de sus principales objetivos durante su gobierno, como las esperadas reformas estructurales, en especial, la energética, la hacendaria y la laboral. En efecto, al inicio de su gobierno había hecho dos declaraciones muy explícitas sobre las características de su gestión. La primera como presidente electo, en una reunión con empresarios alemanes: "Venimos aquí los empresarios mexicanos, venimos aquí como gobierno electo, expresamente a despertar inquietudes en ustedes...”. Y la segunda, ya como presidente en funciones, cuando dijo que el suyo era un "gobierno de empresarios y para empresarios". ${ }^{43}$ Sin embargo, al no tener mayoría en el Congreso, era muy complicado hacer pasar esas reformas. Más allá de las limitaciones derivadas de la

${ }^{42}$ Georgina Sosa, "Democracia, cambio institucional y grupos de poder mediático en México: La 'Ley Televisa' (2005-2007) y la reforma electoral (2006-2008)", tesis de doctorado en Ciencias Políticas y Sociales, campo disciplinario en Sociología, Programa de Posgrado en Ciencias Políticas y Sociales, Universidad Nacional Autónoma de México, 3 de noviembre de 2014, p. 237.

43 M. Luna, "Las asociaciones empresariales...", op. cit., pp. 669-670. 
mala comunicación y del cabildeo, quedó en los empresarios la percepción de que a ese gobierno le faltaba oficio político.

Si no se sentían plenamente satisfechos con el desempeño del ejecutivo, lo estaban aún menos con el del Congreso, donde sus posiciones eran diferenciadas: a veces eran implacables, a veces, agradecidas. Un ejemplo de las primeras es un desplegado del CCE, publicado el 6 de diciembre de 2005, cuando se aprobaron las iniciativas en materia de propiedad industrial, salud y responsabilidad civil por daño y deterioro ambiental. Reclaman a la Cámara de Diputados la rapidez con la que -sin estudios serios ni suficiente discusión sobre las consecuencias económicas, sociales y jurídicas, y sin tomar en cuenta la opinión de los empresarios- aprobaron una ley que afecta la inversión, el empleo, la innovación y la seguridad jurídica. De igual manera, el mismo cCE, respaldado por el conjunto de las organizaciones que representa, en un desplegado de prensa del 3 de septiembre de 2010, acusa a los legisladores de falta de responsabilidad y advierte que se está en un periodo de pobreza legislativa y escasos resultados en cuanto a las reformas estructurales. ${ }^{44}$

En cambio, una muestra de las posiciones agradecidas fue el caso de la controvertida aprobación, en marzo de 2006, de los cambios a la Ley Federal de Telecomunicaciones (LFT) y a la Ley Federal de Radio y Televisión (LFRT), legislación conocida como Ley Televisa. ${ }^{45}$ Esta normatividad que autoriza la desregulación del espectro digital en favor de las dos grandes cadenas de televisión (Grupo Televisa y TV Azteca) fue muy celebrada por algunos empresarios y muy criticada por los expertos, quienes consideraron que las licitaciones no exigen criterios de calidad en la programación en favor del derecho de los ciudadanos a la información y adjudican concesiones con periodos de vigencia excesivamente largos y con posibilidades de renovarse automáticamente sin necesidad de abrir nuevas licitaciones. Fox pudo haber impuesto su veto a esta

${ }^{44}$ Ibid., pp. 672-673.

${ }^{45}$ G. Sosa, op. cit. 
ley ante los señalamientos de la Secretaría de Comunicaciones y Transportes en contra de su aprobación, pero no lo hizo. Georgina Sosa ${ }^{46}$ argumenta, a partir de este caso, que los empresarios manifestaron una imagen de apoyo total a la democracia y a las reglas del juego, pero que diversas acciones mostraron que ese apoyo era sólo discursivo, ya que únicamente apoyan las reglas democráticas cuando favorecen a sus intereses, y se inconforman y transgreden las reglas y las leyes cuando les son desfavorables. Una idea importante que se deriva del trabajo de Sosa es haber propuesto la hipótesis de que los empresarios tienen un compromiso democrático limitado; apoyan el proceso democrático cuando coincide con sus intereses, pero cuando perciben que la democracia los pone en riesgo, dejan de respaldarla y son capaces de violar las reglas del juego y las normas que regulan las relaciones sociales. Según Sosa, para que los empresarios puedan renunciar a su compromiso democrático y lleguen a transgredir las normas, necesitan contar con un margen de maniobra que les otorga el poder ejecutivo o las instituciones reguladoras. Los empresarios pueden desafiar o no a las instituciones de la democracia cuando acontece una combinación de variables: debilidad legal de las instancias reguladoras; que el titular del ejecutivo sea proclive a la permisividad ante los poderes fácticos y que haya alianzas de los miembros de los partidos con los medios.

Por otra parte, uno de los logros del gobierno de Fox fue la creación de órganos autónomos para regular los procesos electorales (Instituto Federal Electoral, ahora Instituto Nacional Electoral, INE) y la transparencia informativa del sector público (Instituto Federal de Acceso a la Información, ahora Instituto Nacional de Transparencia, Acceso a la Información y Protección de Datos Personales, INAI). Sin embargo, en otros ámbitos los empresarios no quedaron satisfechos. Durante la presidencia de Fox y la de Calderón, las principales organizaciones empresariales cabildearon ante los dipu- 
tados para que se aprobaran algunas reformas estructurales. De hecho, durante el gobierno de Calderón se formó la "telebancada", llamada así porque los diputados y senadores del PRI y del PVEM promovieron los intereses de las dos principales televisoras, Televisa y Televisión Azteca (la reforma de las telecomunicaciones), o porque forman parte de la familia de alguno de sus accionistas. De los 18 candidatos al Congreso de la Unión ligados a estas televisoras, 16 formarían parte de las dos cámaras y 11 de ellos eran del PRI y del PVEM. ${ }^{47}$ Con esto, los empresarios de las televisoras ya no

47 Los diputados eran: Rubén Acosta Montoya (PVEM), exdirector ejecutivo de la Comisión Federal de Telecomunicaciones (Cofetel). Antonio Cuéllar Stefan (PVEM), exvicepresidente de asuntos jurídicos de Grupo Televisa. Mónica García de la Fuente (PVEM), que formó parte del departamento jurídico de Televisa. Federico González Luna Bueno (PVEM) exasesor jurídico de la Cámara de la Industria de la Radio y Televisión (CIRT) y de Televisa, y parte del equipo redactor de la ley federal en esa materia. Laura Ximena Martel Cantú (PVEM) fue prosecretaria de la CIRT cuando Tristán Canales, directivo de Televisión Azteca, dirigió el organismo. Javier Orozco Gómez (PVEM), exsenador en la LX Legislatura y diputado en la LIX, fue abogado general de Televisa y promovió las modificaciones a la Ley General de Telecomunicaciones que favorecían a esa empresa. Carla Alicia Padilla Ramos (PVEM) trabajó en el área de noticias de Tv Azteca como jefa de la sección de seguridad y justicia. Simón Valanci Buzali (PRI), empresario chiapaneco propietario de siete emisoras de radio en Chiapas, Tabasco y Veracruz, así como del Diario de Chiapas, de La Voz del Sureste y de la red de telecomunicaciones llamada Súper Cable del Sureste; además, vicepresidente del Consejo Consultivo de la CIRT. Enrique Cárdenas del Avellano (PRI), exdiputado federal en la LX Legislatura, en la que formó parte de la Comisión de Radio, Televisión y Cinematografía, de origen tamaulipeco, también accionista de la Organización Radiofónica Tamaulipeca y de Victoria Radio Publicidad. Jorge Mendoza Garza (PRI), exsenador por Nuevo León, trabajó para TV Azteca como vicepresidente de Asuntos Públicos e Información, fue también presidente del Consejo Directivo de la CIRT.

De los cinco senadores de la telebancada, cuatro militan en el PEvM: Ninfa Salinas Sada, diputada federal en la LXI Legislatura e hija del principal accionista de Grupo Salinas, Ricardo Salinas Pliego. Carlos Alberto Puente Salas, exdiputado federal, exasesor de la CIRT y exjefe de Administración de Convenios Públicos y Gerente de Estrategias y Desarrollo Político en tv Azteca. Juan Gerardo Flores, expresidente de la Comisión de 
sólo tendrían buenos niveles de interlocución con el poder político y los partidos, sino que ejercerían una cuota de poder en el interior de éstos.

La llamada Ley Televisa fue aprobada desde finales del gobierno de Fox, pero la reforma de las telecomunicaciones y otras debieron esperar al sexenio peñista. El propósito del siguiente apartado es examinar las relaciones de los empresarios con el gobierno de Peña Nieto y particularmente dos de las reformas más importantes para los empresarios, la fiscal y la energética.

\section{Los empresarios y el gobierno de EnriQue PeÑa Nieto}

Desde la perspectiva de los empresarios organizados, uno de los mayores logros del gobierno de Peña Nieto fueron las reformas estructurales que, según Juan Pablo Castañón, presidente del CCE, "por décadas parecieron imposibles y [...] hoy ofrecen un renovado rumbo para el país a través de cambios en materia educativa, laboral, de competencia económica, energética y política, además de que ya contamos con leyes para combatir el cáncer de la corrupción”. ${ }^{48}$

De esas reformas, se han seleccionado dos que marcaron de manera particular y contrastada las relaciones en-

Radio y Televisión en la Cámara de Diputados durante la legislatura anterior, y en la Comisión Federal de Telecomunicaciones se desempeñó como director general de Proyectos de Resoluciones y Acuerdos. Luis Armando Melgar Bravo, presidente de la Fundación Azteca Chiapas y director del Canal 40. Arely Gómez González (PRI), hermana de Leopoldo Gómez, vicepresidente de Noticieros Televisa. Véase Dulce Ramos, ¿¿Quiénes llevarán los intereses de las televisoras al Congreso?”, Animal Político, 4 de noviembre de 2012, https://www.animalpolitico.com/2012/09/ telebancadas-quienes-llevaran-los-intereses-de-las-televisoras-al-congreso/ (consulta del 4 de diciembre de 2019).

48 Karla Ponce, "Estas fueron las 11 reformas que marcaron el gobierno de Peña Nieto", Excelsior, 26 de noviembre de 2018, https://www.dine roenimagen.com/economia/estas-fueron-las-11-reformas-que-marcaron -el-gobierno-de-pena-nieto/104937 (consulta del 29 de junio de 2019). 
tre los empresarios y el Estado: la fiscal, contra la que se opusieron, y la energética, la que más les interesaba. Esto no quiere decir que las demás reformas no hayan sido importantes para los empresarios, como la de telecomunicaciones, la laboral o la educativa, sin embargo, nos limitaremos a la fiscal y la energética por razones de espacio y por considerar que eran las más importantes para el empresariado.

\section{La reforma fiscal de Peña Nieto}

México es uno de los países latinoamericanos con ingresos tributarios más bajos de América Latina, si no se tienen en cuenta los derechos sobre la producción de hidrocarburos, y ocupa el último lugar en este rubro entre los países de la oCDE, ya que el último informe de este organismo lo sitúa en el lugar 36, con una proporción de los ingresos tributarios de $16.2 \%$ del PIB, en 2017.

Desde la segunda mitad del siglo xx ha habido varios intentos infructuosos de aumentar la recaudación fiscal en México, ${ }^{49}$ pero se ha recurrido al petróleo como fuente de financiamiento, en lugar de realizar una reforma tributaria.

La última reforma fiscal fue la que promovió el gobierno de Enrique Peña Nieto a través de Luis Videgaray, secretario de Hacienda, discutida en la Cámara de Diputados y aprobada con algunos cambios por la Cámara de Senadores. La propuesta inicial pretendía aumentar la recaudación tributaria en $1.4 \%$ del PIB, en 2014, y llegar a 3\%, en 2018. Los cambios introducidos por los diputados limitarían este aumento a $1.1 \%$ del PIB, en 2014, y a 2.7\%, en 2018, según la Secretaría de Hacienda y Crédito Público (SHCP).

Sin mayoría en ninguna de las cámaras, el gobierno del PRI debió establecer una alianza con el PVEM, con Nueva Alian-

${ }^{49}$ Carlos Elizondo, "In Search of Revenue: Tax Reform in Mexico under the Administrations of Echeverría and Salinas", documento mimeografiado, México, Oxford, cide, Nuffield College, 1992. 
za (Panal) y, sobre todo, con una parte de los senadores del PRD, a cambio de conceder mayores ingresos para la Ciudad de México, entonces bajo el gobierno de este último partido. En conjunto, la aprobación de la reforma, el 30 de octubre de 2013, que entraría en vigor en 2014, contó en el Senado con 73 votos a favor, mientras que la mayoría de los 50 votos en contra provino de los legisladores del PAN, quienes al final abandonaron la Cámara de Senadores, y de una fracción del PRD.

Los principales cambios en la reforma fiscal fueron la aprobación del aumento del impuesto al valor agregado (IVA) en las zonas fronterizas, del $11 \%$ al $16 \%$, para homologarlo con el resto del país, con 68 votos a favor y 55 en contra, estos últimos principalmente del PAN.

También se aprobó cobrar una tasa del impuesto sobre la renta (ISR) de $32 \%$ a quienes tienen ingresos superiores a 750000 pesos al año, de $34 \%$ a quienes perciben más de un millón de pesos y de $35 \%$ a quienes ganan más de tres millones de pesos.

Así mismo, se autorizó gravar con $8 \%$ los refrescos y los alimentos con alto contenido calórico (con más de 275 kilocalorías por cada cien gramos).

Igualmente, se aprobó reducir la deducibilidad de las prestaciones laborales adicionales al salario para las empresas y los individuos, del $100 \%$ que habían gozado hasta entonces, al 53\%; es decir, hacer deducibles de impuestos sólo hasta este porcentaje, los apoyos en seguros de gastos médicos mayores, los vales de despensa y gasolina, la gratificación anual, las horas extras, la prima vacacional y dominical, la participación de los trabajadores en las utilidades, la despensa en especie, las guarderías, el seguro de vida, las actividades culturales y recreativas, la ayuda para transporte, la ayuda escolar y las becas, el fondo de ahorro, el fomento al deporte, los gastos funerarios y otras prestaciones menores.

Los diputados perredistas justificaron la alianza con el PRI argumentando que se trataba de una reforma social. También apoyaron el rechazo a algunos cambios propuestos por el go- 
bierno, como la aplicación del IVA a la renta de casas, y se atribuyeron el aumento del ISR a quienes tuvieran ingresos superiores a 500000 pesos.

La respuesta de los empresarios ante la iniciativa del presidente fue de crítica, en términos generales, al considerar que no contribuiría a la inversión, al crecimiento económico del país, a disminuir la informalidad y a aumentar la base de los contribuyentes.

Como en otras ocasiones, esa ley provocó polémica e inconformidad entre los empresarios organizados. Lo menos que esperaban de un gobernante respaldado por ellos y cercano a sus intereses, es que alentara una reforma que gravaría más los ingresos, a quienes ganan más, y ciertas comidas y bebidas con altas calorías.

Para ellos no fue una reforma hacendaria que permitiera simplificar el régimen fiscal, orientada a mejorar la competitividad y basada en la ampliación de la base de contribuyentes, sobre todo de un sector mayoritario que pertenece a la llamada economía informal o popular. Desde su perspectiva, se trató de una reforma recaudatoria que gravaba más los intereses del sector empresarial, inhibía la inversión y la generación de empleos y, por lo tanto, el crecimiento del país.

Algo que puede parecer sorprendente es que las mayores críticas no se dirigieran contra el aumento de los impuestos a los ingresos, sino a otros temas.

Los principales argumentos de los empresarios contra la reducción de la deducibilidad de las prestaciones es que ésta representa beneficios tangibles para los trabajadores, los cuales redundan en una ganancia para la economía. Además, que "a las empresas les permite, al poder deducir estas prestaciones, utilizar esa liquidez en otros aspectos, como inversión o contratación de empleo". También se señaló que esa reducción precarizaría el mercado laboral y mermaría el poder adquisitivo del sector formal de la economía. Advirtieron que "el costo de esa reducción lo absorbieron algunas empresas, 
otras los eliminaron y los trabajadores resultaron afectados", 50 "Hay que incentivar las prestaciones legítimas que se entreguen para que haya más empresas dando prestaciones", dijo Gustavo de Hoyos, presidente de la Coparmex. ${ }^{51}$ Por su parte, los representantes de la iniciativa privada de Nuevo León indicaron que las empresas más afectadas por la reducción de la deducibilidad eran las pequeñas y medianas, porque se restringía la deducibilidad de muchos gastos; además, indicaron, "las asociaciones civiles también resultarán afectadas porque se restringirán los donativos al bajarse la deducibilidad". Por otra parte, advirtieron que la reforma daba la pauta para que muchos giros se mantuvieran en la informalidad, como los restaurantes y los médicos. ${ }^{52}$ Los organismos empresariales de Monterrey habían propuesto una reforma fiscal que consistía en ampliar la base de contribuyentes y consideraron que la enviada por el presidente al Congreso consistía en "cargarle más a los mismos". ${ }^{53}$ Sin embargo, uno de los aspectos que los empresarios consideraron positivo de la reforma fue la eliminación del impuesto empresarial a tasa única (IETU).

La principal oposición a la homologación del IVA en la frontera con Estados Unidos a la tasa del 16\% provino del PAN, partido que tiene una parte de su electorado en esta región norteña. El argumento fue que no se deberían aumentar los impuestos cuando México padecía una desaceleración económica. Ernesto Cordero, líder del PAN en el Senado, afirmó que "en un momento donde se están perdiendo empleos en México, qué necesidad hay de quitarle recursos a las familias para dárselos al gobierno, qué necesidad de quitarle recursos a todos aquellos que abren fuentes de empleo".

Entre los principales representantes de los empresarios que manifestaron su desacuerdo estuvieron Gustavo de Ho-

50 Leticia Hernández, “¿A quién beneficia que sean deducibles al $100 \%$ las prestaciones laborales?”, El Financiero, 18 de diciembre de 2018.

51 Loc. cit.

${ }^{52}$ Juan Antonio Lara, "Decepciona a empresarios de NL reforma fiscal", El Financiero, 10 de septiembre de 2013.

${ }^{53}$ Loc. cit. 
yos, presidente de la Coparmex; Juan Pablo Castañón, presidente del CCE; Claudio X. González, presidente del CMN, y Francisco Funtanet Mange, presidente de la Concamin, así como el Consejo de Cámaras Industriales de Jalisco, CCIJ, y la Cámara de la Industria de la Transformación (Caintra).

Por su parte, la Coparmex propuso a todos los organismos empresariales del país realizar tres acciones frente a la reforma fiscal: 1) Solicitar al gobierno federal la integración de un grupo de alto nivel que analizara un auténtico proyecto de política fiscal, ya que ésta no podía "ni de lejos considerarse una reforma fiscal, si acaso, miscelánea"; 2) "Exigir la creación de un programa de apoyo a las fronteras -sobre todo a la del norte-, que resentirán en empleo y ventas la homologación del IVA a 16\%", 3) "Exigir y, en su caso, proponer mecanismos para reducir -lo ideal es desaparecer- la economía informal, para lo que se propone la emisión de una cédula que no sólo sirva como identificación, sino que tenga utilidad también para realizar trámites fiscales como una medida de control". También se indicó que "cada centro empresarial en los estados es libre de publicar, como ha hecho ya en algunas entidades, las fotos y nombres de los legisladores que votaron a favor de la reforma fiscal, a pesar del llamado que hizo el coordinador de los legisladores del PRD, Silvano Aureoles, quien advirtió sobre posibles 'atentados' por esa práctica”. ${ }^{54}$

Para principios de marzo de 2014, la reforma fiscal había originado cerca de 10000 amparos de las empresas de distintos sectores y, según declaraciones de los empresarios, provocaría el despido de personal y la reducción o eliminación de prestaciones salariales. Sin embargo, estos amparos finalmente no prosperaron. Juan Pablo Castañón, presidente de la Coparmex (2012-2015), aclaró que las posturas de las empresas fueron diferentes: algunas estaban reduciendo

54 Adrián Trejo García, "Quieren empresarios reforma fiscal en serio", El Financiero, 5 de noviembre de 2013. 
personal y cortando ciertas prestaciones salariales para poder absorber los nuevos costos; otras determinaron recurrir al amparo; otras más, cuando les resultaba viable, se esforzaban por absorber los gastos y evitar el despido. Las empresas más afectadas, según este representante de la Coparmex, fueron las que utilizan de manera intensiva la mano de obra y al mismo tiempo tienen muchas prestaciones, porque el costo laboral impacta mucho en el del servicio del bien que producen; esas empresas se verían afectadas hasta en un $30 \%$. Tal es el caso de las empresas de outsourcing o subcontratación de servicios. Además de los efectos negativos para las empresas existentes, el dirigente empresarial consideró que este impuesto inhibiría la creación de nuevos proyectos productivos en algunos rubros de la economía. ${ }^{55}$

En resumen, la reforma fiscal elevó las tasas máximas de ISR para las personas físicas y no las cambió para las empresas, creó diversos impuestos especiales y eliminó la tasa diferenciada del IVA en las fronteras pero, del mismo modo que durante la administración de Felipe Calderón, tampoco aplicó IVA a alimentos y medicamentos -hasta ahora exentos-, una idea que el PAN ha impulsado. Éste hizo campaña también para que las colegiaturas se mantuvieran exentas del pago del Iva, lo que sí consiguió.

La reforma fiscal tenía como propósito principal mejorar las finanzas públicas, más que promover un mayor crecimiento económico o atraer inversiones. Como resultado, sí se obtuvo una mayor recaudación, sobre todo en los primeros años. Entre 2013 y 2016, el crecimiento real de los ingresos tributarios fue de $58.4 \%$, a una tasa promedio anual de $15.3 \%$, mientras que el crecimiento promedio de la economía fue de sólo 2\%. Esa mayor recaudación fiscal compensó la caída de los ingresos petroleros en el mismo periodo. Además, el aumento de la recaudación no provino principalmente del incremento en algunas tasas sino, sobre todo,

${ }^{55}$ Angélica Hernández, "Empresarios presentan 10 mil amparos ante reforma fiscal", El Financiero, 5 de marzo de 2014. 
de la ampliación de la base de contribuyentes, que pasó de 41 millones de personas físicas y morales a 61 millones. A precios de 2017, la recaudación significó 1.6 billones de pesos, equivalentes a cerca de $7.7 \%$ del PIB, más del doble de los tres puntos porcentuales que se esperaban. ${ }^{56}$

\section{Los empresarios y la reforma energética}

Enrique Peña Nieto inició su mandato con un logro político: el Pacto por México, firmado por el PRI, el PAN y el PRD al día siguiente de asumir el poder. Este acuerdo político nacional pretendía tener una amplia cobertura para incidir sobre el Estado, la economía y la política, los derechos sociales y la participación de los ciudadanos en las políticas públicas. Del pacto se derivaron varias reformas, entre las más importantes, la educativa, la de telecomunicaciones, la laboral, la financiera, la fiscal y la energética. Esta última permitiría al gobierno avanzar en una de las aspiraciones de los grandes empresarios mexicanos y de las empresas transnacionales. Ninguno de los gobiernos anteriores, desde la expropiación petrolera, en 1938, había abierto de manera significativa los energéticos a la participación privada. Así, con esta reforma se abandonaba el último de los sectores en los que la explotación era exclusiva del Estado y con ello se rompía un tabú, lo que la convirtió en un hito histórico. Según el acuerdo, teóricamente, se promovería una reforma en la que los hidrocarburos se mantendrían como propiedad de la nación y serían manejados con transparencia, como una empresa corporativa que permitiera la ampliación de la exploración y la producción, así como la competencia en los procesos de refinación, petroquímica y transporte de hidrocarburos, en la que Petróleos Mexicanos (Pemex) no sería privatizada. Además, se dio "a Pemex la potestad para elegir qué zonas mantendría; esto

${ }^{56}$ Enrique Quintana, "Una reforma impopular pero efectiva", El Financiero, 23 de noviembre de 2017. 
es, Pemex fue el primero en acceder a la repartición del 'pastel petrolero' mexicano. Desde luego, con la enorme ventaja de ser poseedor del total de la información geológica sobre reservas". 57

La modificación de los artículos 25, 27 y 28 de la Constitución abrió el sector energético a la participación de empresas privadas en exploración y producción a través de diversos tipos de contratos: servicios, utilidad compartida, producción compartida y licencias. Esto significa que el Estado estaría en capacidad de firmar contratos con empresas nacionales y extranjeras, que podrían explorar, explotar y transportar el petróleo. El mayor incentivo para los empresarios mexicanos era que se les permitiría participar en un negocio que, si bien tenía alto riesgo, también ofrecería la oportunidad de obtener grandes ganancias en la explotación, la extracción, la petroquímica, los servicios, la distribución, el almacenamiento, el gas y la electricidad.

El órgano regulador del sector que licitaría los contratos de asociación sería la Comisión Nacional de Hidrocarburos (CNH), mientras que la Secretaría de Energía (SE) definiría los lineamientos técnicos y contractuales de esas asociaciones, y la SHCP establecería las condiciones fiscales. En cuanto a su dimensión organizativa y política, en el Consejo de Administración de Pemex dejarían de participar los cinco representantes del Sindicato de Trabajadores Petroleros de la República Mexicana (sTPRM).

Algunas de las interrogantes que surgieron sobre la reforma fueron si los cambios llevarían a una real transparencia, si podría elevarse la producción de hidrocarburos y reducir las importaciones de gasolina y gas, si podría asegurarse la protección del medio ambiente y si, con esta reforma, podrían atraerse inversiones a las aguas del Golfo de México, donde

57 "La reforma energética, la participación privada y el descubrimiento gigante", México, Unidad de Análisis Estratégico, Connection México Global, 2017, http://www.connectionmexicoglobal.com/wp-content/ uploads/2017/08/RE-Sierra-Oil-P.pdf 
están las principales reservas de petróleo nacional. Desde el principio aparecieron empresas mexicanas interesadas en participar activamente y en hacer negocios en el sector energético, como Alfa, Alpek, Cemex, Grupo Carso e ICA. ${ }^{58}$

Aunque las actividades cruciales del sector energético han sido exclusivas del gobierno mexicano, desde antes de la reforma había empresas petroleras privadas con experiencia y negocios en el sector, porque proveían a Pemex de insumos para la producción. ${ }^{59}$ Por ejemplo, el tamaulipeco José Ramiro Garza Cantú, propietario del diario La Razón, fundó el Grupo R desde 1960. Este ha participado en el desarrollo de yacimientos como Cantarell y Ku-Maloob-Zaap; desde 2003, opera un yacimiento de gas y, desde 2007, realiza inversiones para la perforación en aguas profundas. ${ }^{60}$ Otra empresa con tradición en el sector petrolero es el Grupo Diavaz, fundado por los hermanos Luis y Óscar Vázquez Sentíes, en 1973, como una empresa de servicios de buceo para plataformas, con presencia en 13 estados. El fondo estadounidense Evercore, que maneja fondos de retiro, presidido por Pedro Aspe, es dueño de $20 \%$ de Diavaz. TAmsa (ahora Ternium Tenaris, empresa italo-argentina), desde sus inicios como empresa mexicana proveyó de tubos sin costura a Pemex. El Grupo Carso, de Carlos Slim, cuenta también con experiencia y vínculos con el sector petrolero a través de Swecomex, que construye plataformas para Pemex, y de Servicios Integrales GSM, que perfora pozos terrestres. Germán Larrea, de Grupo México, presta servicios de perforación desde 1959 a través de Perforadora México y en los últimos tres años invirtió 1200 millones de dólares en seis plataformas que renta a

${ }^{58}$ Leticia Robles de la Rosa, "PRD resquebraja Pacto por México; busca detener la reforma energética”, Excélsior, 29 de noviembre de 2019.

${ }^{59}$ Luis Miguel González, "Petroleras privadas mexicanas: ¿quién es quién?”, El Economista, 13 de julio de 2017, https://www.eleconomista. com.mx/opinion/Petroleras-PRIvadas-mexicanas-quien-es-quien-2017 0714-0001.html

60 "Los 300 empresarios", Lideres Mexicanos, https://lideresmexica nos.com/300/jose-ramiro-garza-cantu-los-300/ 
Pemex. ${ }^{61}$ Grupo Alfa, presidido por Armando Garza Sada, ha invertido en hidrocarburos fuera de México y esperaba la apertura del sector energético para participar. Otras empresas proveedoras de Pemex son ICA Flour Daniel, del Grupo ICA; Cotemar; Dragados Offshore de México; Demar Instaladora y Constructora; Constructora Subacuática Diavaz; DGMGP Servicios de Integridad; Servicios Marítimos Campeche; ARB Arendal; Iberoamericana de Hidrocarburos; Servicios Múltiples de Burgos, y Grupo Evya. ${ }^{62}$

Con la apertura del sector energético, una treintena de empresas mexicanas (véase cuadro 2) obtuvieron la licitación en las dos primeras rondas. ${ }^{63}$

\section{Cuadro 2}

Empresas mexicanas que obtuvieron adjudicaciones en las rondas de licitación de 2017

\begin{tabular}{|l|l|c|}
\hline \multicolumn{1}{|c|}{ Nombre } & \multicolumn{1}{c|}{ Grupo } & Ronda \\
\hline Sierra Oil \& Gas & Sierra Oil \& Gas & 1 \\
\hline Petrobal & Grupo Bal & 1 \\
\hline Diavaz & Grupo Diavaz & 1 \\
\hline Desarrolladora Oleum & Desarrolladora Oleum & 1 \\
\hline Marat International & Marat International & 1 \\
\hline Constructora Tzaulan & Constructora Tzaulan & 1 \\
\hline Consorcio Manufacturero Mexicano & Consorcio Manufacturero Mexicano & 1 \\
\hline Grupo Diarqco & Grupo Diarqco & 1 \\
\hline
\end{tabular}

61 "Él es el petrolero 'no. 1 de México'... después de Pemex", SIPSE. сом, https://sipse.com/mexico/reforma-energetica-grupo-diavaz-prepara-inversion-apertura-pemex-144951.html

${ }^{62}$ Noé Cruz Serrano, "Pemex favorece a 21 firmas proveedoras en el sexenio", El Universal, 2 de mayo de 2018, https://www.eluniversal.com. $\mathrm{mx} /$ cartera/pemex-favorece-21-firmas-proveedoras-en-el-sexenio

${ }^{63}$ Ey México, Nueva era de la energía en México, Ministerio Federal de Economía y Energía de la República Federal de Alemania /Secretaría de Energía de México, México, 2018, https://www.energypartnership.mx/ fileadmin/user_upload/mexico/media_elements/reports/NuevaEraE nergiaMexico_ESP.pdf 


\section{Cuadro 2 (conclusión)}

Empresas mexicanas que obtuvieron adjudicaciones en las rondas de licitación de 2017

\begin{tabular}{|l|l|c|}
\hline \multicolumn{1}{|c|}{ Nombre } & \multicolumn{1}{|c|}{ Grupo } & Ronda \\
\hline Perfolat de México & Perfolat de México & 1 \\
\hline $\begin{array}{l}\text { Servicios de Extracción Petrolera Lifting } \\
\text { de México }\end{array}$ & $\begin{array}{l}\text { Servicios de Extracción Petrolera Lifting } \\
\text { de México }\end{array}$ & 1 \\
\hline Strata Campos Maduros & Strata BPS & 1 \\
\hline Sistemas Integrales de Compresión & Grupo Nuvoil & 1 \\
\hline Nuvoil & Nuvoil & 1 \\
\hline Constructora Marusa & Constructora Marusa & 1 \\
\hline Streel Serv & Grup Hosto & 1 \\
\hline Constructora Hostotipaquillo & $\begin{array}{l}\text { Desarrollo de Tecnología y Servicios } \\
\text { Integrales }\end{array}$ & 1 \\
\hline $\begin{array}{l}\text { Desarrollo de Tecnología y Servicios } \\
\text { Integrales Mercado de Arenas Sílicas }\end{array}$ & Mercado de Arenas Sílicas & 1 \\
\hline Grupo R - Oil \& Gas Company & Grupo R & 1 \\
\hline Constructora y Arrendadora México & Constructora y Arrendadora México & 1 \\
\hline Compañía Petrolera Perseus & Compañía Petrolera Perseus & 1 \\
\hline Tonalli Energía & Grupo IDESA y Petrofrontera & 1 \\
\hline $\begin{array}{l}\text { Construcciones y Servicios Industriales } \\
\text { Globales Pemex }\end{array}$ & $\begin{array}{l}\text { Construcciones y Servicios Industriales } \\
\text { Globales }\end{array}$ & 1 \\
\hline Pemex 1 & Pemex 1 & 1 \\
\hline Sierra Perote E\&P & Sierra Perote E\&P & 2 \\
\hline Citla Energy E\&P & Citla Energy E\&P & 2 \\
\hline Iberoamericana de Hidrocarburos & $\begin{array}{l}\text { Monclova Pirineos Gas (México) y 2 } \\
\text { Cobra Instalaciones y Servicios (Espana) }\end{array}$ & 2 \\
\hline Servicios PJP4 de México & Servicios PJP4 de México & 2 \\
\hline Jaguar Exploración y Producción & Grupo Topaz & 2 \\
\hline sicovaL mX & SICovaL Mx & 2 \\
\hline Nuevas Soluciones Energéticas A\&P & Nuevas Soluciones Energéticas A\&P & 2 \\
\hline Carso Oil \& Gas & Carso Energy (Grupo Carso) & 1 \\
\hline Newpek Exploración y Extracción & Grupo Alfa & 1 \\
\hline & & 2 \\
\hline
\end{tabular}

* La CNH adjudica los servicios de comercialización de hidrocarburos en estado líquido y gaseoso.

Fuente: Ernst \& Young (EY), con información del Gobierno de México y la Comisión Nacional de Hidrocarburos ( $\mathrm{CNH})$, Reservas de hidrocarburos en México, conceptos fundamentales y análisis, 2018, y Gobierno de México y la Comisión Nacional de Hidrocarburos ( $\mathrm{CNH})$, Bóveda digital de contratos de la $\mathrm{CNH}$. 
Estas empresas mexicanas ganadoras en las licitaciones presentan distintas características. Por una parte, están los intereses de algunos grandes grupos económicos de México, varios de ellos miembros del CMN. Los más destacados se consignan a continuación.

Petrobal, de Alberto Baillères (las industrias mineras Peñoles y Fresnillo, aseguradora GNP, El Palacio de Hierro, ITAM), quien contrató a Carlos Morales Gil como director general, un alto directivo de Pemex durante más de treinta años y que de 2004 a 2014 fue director de Pemex Exploración y Producción, la unidad más importante de Pemex. Jaguar, del Grupo Topaz (con intereses en el sector energético, educativo e inmobiliario, dirigido por Dionisio Garza Sada, hijo de Dionisio Garza Medina, expresidente del Grupo Alfa. Carso Oil \& Gas, fundada en 2014, forma parte de Carso Energy (Grupo Carso), de Carlos Slim, y opera en exploración y producción, perforación y arrendamiento de plataformas. Newpek, del Grupo Alfa, presidido por Armando Garza Sada, es una empresa del sector energético, en especial en exploración y desarrollo del petróleo y gas natural, principalmente en Estados Unidos y México.

Existe otro grupo de empresas que se relacionaron con Pemex, ya sea como proveedoras desde hace muchos años o como productoras del hidrocarburo. Algunas de éstas nacieron a pequeña escala en las regiones petroleras y otras fueron creadas por directivos de Pemex que aprovecharon su conocimiento y redes sociales y políticas. A continuación, las mencionamos:

Diavaz, presidida por Luis Vázquez, empezó hace cuarenta años como una pequeña empresa de servicios de buceo para plataformas y llegó a tener 500 buzos. Diavaz es el mayor productor nacional de petróleo después de Pemex y uno de los principales proveedores en México de servicios al sector petrolero para trabajos de buceo, construcción, mantenimiento y modernización de plataformas y ductos, exploración, perforación y producción de petróleo, y operación y distribución de gas. Sus tres divisiones (operaciones marinas, ex- 
ploración y producción, y gas) sumaron en 2014 cerca de 1200 millones de dólares en ventas. ${ }^{64}$

Sistemas Integrales de Compresión forma parte del Grupo Nuvoil, presidido por el empresario veracruzano Mariano Hernández Palmeros, quien ha sido gestor y representante de compañías internacionales que desarrollan proyectos tecnológicos para la industria del petróleo y gas, entre ellos, la planta de mecanismo de desarrollo limpio Tres Hermanos, ubicada en Poza Rica, Veracruz; el proyecto piloto de una planta de inyección de aire, ubicada en Villahermosa, Tabasco; el sistema de compresión de gas amargo sobre una plataforma autoelevable tipo jack up, en el campo Cantarell, en el Golfo de México, y el desarrollo y operación de sistemas artificiales de producción. Las empresas Diverse Energy Systems LLC, en propuesta conjunta con Grupo Exsen, Tinglo y Sistemas Integrales de Compresión, todas integrantes del Grupo Nuvoil, participaron en la licitación del contrato denominado "Servicio integral de bombeo hidráulico para pozos de aceite en la región norte". Sistemas Integrales de Compresión se hizo acreedora a una inhabilitación de casi un año porque "no informó a Pemex que la empresa Diverse Energy Systems se declaró en quiebra, lo que es causal de rescisión de contrato". 65

Constructora Marusa es una empresa con sede en Tabasco que participa desde hace treinta años en el sector de petróleo y gas, donde ofrece servicios de construcción relacionados con obras electromecánicas en ductos, vías de acceso y pavimentación, y obras civiles, como cercado perimetral y estructuras de soporte de ductos. En 2015, Constructora Marusa se adjudicó una licitación por el bloque Benavides Primavera en Nuevo León, México, como parte

64 "Él es el petrolero...", op. cit.

65 J. Jesús Rangel M., "Prácticas ilegales por contratos de Pemex", Milenio, 29 de diciembre de 2016, https://www.milenio.com/opinion/ jesus-rangel/estira-afloja/practicas-ilegales-por-contratos-de-pemex 
de Consorcio Petrolero 5M del Golfo, junto con Sistemas Integrales de Compresión y Nuvoil. ${ }^{66}$

Servicios de Extracción Petrolera Lifting de México, con sede en Ciudad del Carmen, Campeche, es filial del proveedor de servicios costa afuera Cotemar. ${ }^{67}$ Dirigida por Alejandro Villarreal Martínez y propiedad de Mario Dávila Dávila y María Cristina Lobo Morales, construye viviendas, ductos, y plataformas; presta servicios de hospedaje y alimentos, y renta lanchas y buques. Ha sido objeto de controversias porque es una de las empresas que ha logrado más convenios directos de Pemex en los últimos tres sexenios, así como por los accidentes que han ocurrido en algunas de sus obras. En el sexenio de Peña Nieto se le otorgaron contratos por cerca de 44340 millones de pesos. ${ }^{68}$

El Grupo IDESA, con raíces en grupos empresariales y políticos de mediados del siglo xx, fue fundado por Pascual Gutiérrez Roldán, un cercano colaborador del presidente Adolfo López Mateos y director general de Pemex, de 1958 a 1964. Actualmente, al grupo, dirigido por su hijo Guillermo Gutiérrez Saldívar, le interesa no sólo el petróleo, sino también sus derivados. IDESA es la socia mexicana (minoritaria) de la empresa brasileña Braskem, filial de Odebrecht, con la que participa en Etileno XXI, un complejo petroquímico de 4720 millones de dólares, ubicado en Coatzacoalcos, Veracruz, y el más grande construido en México en los últimos treinta años, y produce polietileno y

66 "Constructora Marusa, SA de CV (Constructora Marusa)", BNamericas, https:/ / www.bnamericas.com/es/perfil-empresa/constructora-marusa-sa-de-cv-constructora-marusa

67 Servicios de Extracción Petrolera Lifting de México, SA de CV (Servicios de Extracción Petrolera Lifting de México), BNamericas, https://www.bnamericas.com/es/perfil-empresa/servicios-de-extrac cion-petrolera-lifting-de-mexico-sa-de-cv-servicios-de-extraccion-petro lera-lifting-de-mexico

68 Rubén Zermeño, “Cotemar, empresa consentida y polémica”, Reporte Índigo, 12 de julio de 2018. 
otros derivados que son la materia prima de muchas industrias. ${ }^{69}$

En el debate electoral del 12 de junio, el candidato José Antonio Meade denunció que la familia política de Javier Jiménez Espriú, colaborador cercano de López Obrador y actual secretario de Comunicaciones y Transportes, e incluso su esposa, son socios de IDESA, a su vez socia de Braskem, la filial de Odebrecht que participa en el mencionado complejo Etileno XXI. Jiménez Espriú respondió que su suegro fue el propietario de IDESA y reconoció que su esposa posee acciones, pero se deslindó de toda relación con el caso Odebrecht. ${ }^{70}$

Además de las mexicanas, diversas empresas extranjeras obtuvieron licitaciones para participar en la industria petrolera (véase el cuadro 3). El país con más empresas que ganaron licitaciones es Estados Unidos (8), seguido del Reino Unido (4) y después Colombia (3). Les siguen Canadá (2), China (2) y Holanda (2) y, finalmente, Alemania (1), Argentina (1), España (1), Francia (1), Italia (1), Japón (1), Malasia (1), Noruega (1) y Rusia (1). Algunas de estas empresas figuran entre las más grandes e importantes de sus países. Una característica relevante de varias de ellas es que provienen no sólo de los países más desarrollados, sino que en algunos casos tienen su sede en países emergentes, como Argentina, China, Colombia y Malasia.

En 2018, y a tres años de haberse aprobado la reforma, según el titular de la Secretaría de Energía, se habían firmado inversiones por más de 82327 millones de dólares en proyectos de exploración, extracción de hidrocarburos, sísmica para exploración, gasoductos y energía limpia. En el marco

69 Zacarías Ramírez Tamayo, "Grupo IDEsA, tras un mercado energético de 2500 mdd", Forbes, 20 de octubre de 2016, https://www.forbes. com.mx/grupo-idesa-tras-un-mercado-energetico-de-2500-mdd/

70 "La familia política de Javier Jiménez Espriıú, colaborador de AMLO, es socia de filial de Odebrecht”, Vanguardia.mx, 13 de junio de 2018, https:/ / vanguardia.com.mx/articulo/la-familia-politica-de-javier-jimenez-espriucolaborador-de-amlo-es-socia-de-filial-de 
de siete licitaciones realizadas, se firmaron 72 nuevos contratos con inversiones por 59000 millones de dólares "y no hay ni una sola impugnación o queja de empresas participantes". Además, estaban previstas las subastas en energía limpia y tres licitaciones petroleras. El propio secretario informó sobre la diversificación del mercado petrolero, con treinta nuevas marcas de gasolineras, seis de las cuales son internacionales y 24 mexicanas, con lo que -según dijo- los consumidores ya podrían elegir entre distintos precios, calidad y marcas de gasolinas, al ya no haber un precio único de combustible para todo el país. ${ }^{71}$

Es cierto que estas inversiones requieren de mucho tiempo para desarrollarse y mostrar resultados económicos y sociales. Sin embargo, en 2018 se hizo una encuesta entre 900 empresarios para evaluar los resultados de la reforma energética a cuatro años de su aprobación; ${ }^{72}$ sus resultados indicaron que seis de cada diez consideraron que la reforma había afectado de manera negativa la competitividad de sus empresas, de acuerdo con el reporte Perspectivas de la Alta Dirección en México 2018, elaborado por la consultora KPMG. Para un socio líder nacional de asesoría de la consultora que hizo el estudio, esta respuesta de los empresarios "no es razonable con base en las inversiones que se han comprometido en México por más de 160000 millones de dólares”. El principal reclamo de los empresarios y, en general, de la población, es que los aumentos en el precio de la gasolina y el estancamiento de las tarifas eléctricas han afectado los negocios y los gastos de las familias.

71 "Inversiones en el sector energético en México superarán los 100,000 mdd en 2018”, Economiahoy. $m x$, 9 de enero de 2018, https:/ / www. economiahoy.mx/economia-eAm-mexico/noticias/8856227/01/18/In versiones-en-el-sector-energetico-en-Mexico-superaran-los-100000-mdden-2018.html

72 Arturo Solís, "La reforma energética tuvo impacto negativo: empresarios", Forbes, 18 de abril de 2018. 


\section{Cuadro 3 \\ Empresas extranjeras que lograron adjudicaciones en las rondas de licitación de 2017}

\begin{tabular}{|c|c|c|c|}
\hline País & Nombre & Grupo & Ronda \\
\hline Alemania & Deutsche Erdöl AG & Li Energy & 2 \\
\hline Argentina & E\&P Hidrocarburos y Servicios & Pan American Energy LLC & 1 \\
\hline \multirow[t]{2}{*}{ Canadá } & Renaissance Oil Corp & Reinaissance Oil Corp & 1 \\
\hline & Sun God Energía de México & Sun God Resources & 2 \\
\hline \multirow[t]{2}{*}{ China } & China Offshore Oil Corporation E\&P México & CNOOC & 1 \\
\hline & Shandong Kerui Oilfield Services Group & Kerui Group & 2 \\
\hline \multirow[t]{3}{*}{ Colombia } & Industrial Consulting & Industrial Consulting & 1 \\
\hline & $\begin{array}{l}\text { Ingeniería Construcciones y Equipos Cone- } \\
\text { quipos }\end{array}$ & Conequipos & 1 \\
\hline & Ecopetrol & Ecopetrol & 2 \\
\hline España & Repsol Exploración México & Repsol & 2 \\
\hline \multirow[t]{8}{*}{ Estados Unidos } & American Oil Tools & American Oil Tools & 1 \\
\hline & Chevron Energía de México & Chevron Corporation & 1 \\
\hline & $\begin{array}{l}\text { ExxonMobil Exploración y Producción } \\
\text { México. Fieldwood Energy LLC }\end{array}$ & ExxonMobil & 1 \\
\hline & Fieldwood Energy LLC & Fielwood Energy & 1 \\
\hline & GX Geoscience Corporation & ION Geophysical & 1 \\
\hline & Murphy Worldwide & Murphy Oil Corporation & 1 \\
\hline & Roma Energy Holdings & Roma Energy Holdings & 1 \\
\hline & Verdad Exploration Mexico LLC & Verdad Oil and Gas & 2 \\
\hline Francia & Total & Total & 1 y 2 \\
\hline \multirow[t]{2}{*}{ Holanda } & Canamex Dutch & Canamex Resources & 1 \\
\hline & Shell Exploración y Extracción de México & Royal Dutch Shell & 2 \\
\hline Italia & Eni International & Eni International & 1 y 2 \\
\hline Japón & Inpex Corporation & Inpex Corporation & 1 \\
\hline Malasia & PETRONAS Carigali International & PETRONAS & 1 y 2 \\
\hline Noruega & Statoil E\&P México & Statoil ASA & 1 \\
\hline \multirow[t]{4}{*}{ Reino Unido } & BP Exploration México & BP Global & 1 \\
\hline & Ophir México & Ophir Energy & 1 \\
\hline & Premier Oil & Premier Oil & 1 \\
\hline & Capricorn Energy & Cairn & 2 \\
\hline Rusia & Lukoil Overseas Netherlands & Lukoil & 2 \\
\hline
\end{tabular}

* La CNII adjudica los servicios de comercialización de hidrocarburos en estado líquido y gaseoso.

Fuente: Ernst \& Young (EY), con información del Gobierno de México y la Comisión Nacional de Hidrocarburos $(\mathrm{CNH})$, Reservas de hidrocarburos en México, conceptos fundamentales y análisis, 2018, y Gobierno de México y la Comisión Nacional de Hidrocarburos ( $\mathrm{CNH})$, Bóveda digital de contratos de la CNH. 
De hecho, en esta consulta la reforma mejor calificada por los empresarios en cuanto su impacto en la competitividad de sus empresas fue la de telecomunicaciones (74\% positivo), seguida de la laboral y la financiera $(51 \%)$, la educativa $(49 \%)$, la energética (42\%) y, finalmente, la fiscal (26\%).

En septiembre de 2018, después de su triunfo electoral, López Obrador, acompañado del futuro director general de Pemex, Octavio Romero, y de la futura secretaria de Energía, Rocío Nahle, invitó exclusivamente a los empresarios mexicanos del sector petrolero a una reunión en Villahermosa Tabasco. Unos días antes, Nahle había dado a conocer que del presupuesto de Pemex se destinarían 135000 millones de pesos para exploración y perforación, $55000 \mathrm{mi}-$ llones a la construcción de la primera etapa de la nueva refinería de Dos Bocas y 5000 millones para las seis refinerías en operación: Francisco I. Madero, en Ciudad Madero, Tamaulipas (fundada en 1914); Salamanca, Guanajuato (1950); Minatitlán, Veracruz (1956); Tula, Hidalgo (1976); Cadereyta, Nuevo León (1979), y Salina Cruz, Oaxaca (1979). Entre los asistentes estuvieron Miguel Alemán Magnani, de Grupo Galem; José Ramiro Garza Vargas, de Grupo R; Adolfo del Valle, de Perforadora Latina; la familia Lobo, del Grupo Protexa; Guadalupe Philips, de ICA; Luis Vázquez, del Grupo Diavaz; Patricio Álvarez Murphy, de Perforadora Central, y Carlos Slim, de Operadora CICSA. En cambio, no se convocó a la reunión a las empresas petroleras transnacionales. Además, es de señalarse que tampoco estuvieron presentes Alberto Baillères (Petrobal), Germán Larrea (Perforadora México), María Cristina Lobo Morales y su marido, Mario Dávila Dávila (Cotemar), con quienes el candidato a la presidencia había tenido enfrentamientos.

En esa reunión, López Obrador pidió a los empresarios que lo ayudaran a reactivar la producción petrolera del país, que estaba en crisis, ya que había pasado de 3.4 millones de barriles diarios, en 2004, a 1.8 millones, en 2018. La idea era reactivar la producción de crudo y, por 
lo pronto, llegar a 2.4 millones de barriles diarios para finales de $2019 .{ }^{73}$

Más adelante, ante la incertidumbre sobre el futuro del sector energético en el marco de la nueva administración, un grupo de empresarios visitó a López Obrador en Palacio Nacional poco después de que asumiera el cargo de presidente. ${ }^{74}$ El grupo en su conjunto salió optimista de la reunión. ${ }^{75}$ Todos los empresarios coincidieron en que la reunión había sido muy positiva y que estaban dispuestos a invertir y trabajar con Pemex y la Secretaría de Energía para aumentar la producción de crudo. Comentaron que estaban trabajando en contratos de exploración y de desarrollo. Sobre su certidumbre en relación con los contratos a futuro, consideraron que el presidente de México había sido muy claro: en la medida en que las empresas cumplieran con sus contratos, el Estado continuaría ayudando y apoyando para que sus inversiones tuvieran buen término. Enfatizaron el completo respaldo del presidente y de su equipo de trabajo para el éxito de estos proyectos y el bien de México; también manifestaron su apoyo en todo a López Obrador, siempre y cuando fuera para beneficio del país.

En el tema del petróleo los empresarios nacionales y el capital extranjero tienen posiciones diferenciadas. Los que

${ }^{73}$ Mario Maldonado, "Los mensajes de AMLo a los petroleros", El Universal, 12 de septiembre de 2018, https:/ / www.eluniversal.com.mx/columna/mario-maldonado/cartera/los-mensajes-de-amlo-los-petroleros

${ }^{74}$ Entre los principales empresarios estuvieron Miguel Alemán Magnani, presidente del Consejo de Interjet; Olegario Vázquez Aldir, de Grupo Ángeles; Alberto de la Fuente, director general de Shell México, quien acudió a la reunión como presidente de la Asociación Mexicana de Empresas de Hidrocarburos (AMEXHI); Carlos Hank González, presidente de Grupo Financiero Banorte; Bernardo Gómez, vicepresidente de Televisa; Ricardo Salinas Pliego, presidente de Grupo Salinas; Miguel Rincón, de Biopappel, y Miguel A. Loya, presidente de Vitol.

${ }_{75}$ Rocío Méndez, "Redoblarán empresarios esfuerzos e inversiones en el sector energético", mVs Noticias, 16 de enero de 2019, https://mvsnoticias.com/noticias/nacionales/redoblaran-empresarios-esfuerzos-einversiones-en-el-sector-energetico/ (consulta del 15 de junio de 2019). 
han conseguido las licitaciones están invirtiendo, aunque no al ritmo esperado, y no hay ninguna señal de que la reforma energética vaya a revertirse. Algunos de los empresarios que tuvieron enfrentamientos con López Obrador y que tienen licitaciones han estado buscando un acercamiento con él, como Alberto Baillères, quien durante la campaña electoral trató de que el personal que trabaja en sus empresas no votara por el candidato de Juntos Haremos Historia pero que, después de su triunfo le envió una carta de respaldo en relación con la misiva de López Obrador a Trump, en la que responde a la amenaza de imponer aranceles a productos mexicanos. Después de felicitarlo y expresarle su apoyo y simpatía, Baillères le dice que "tanto el contenido, como el tono de su carta, con dignidad y decoro, muestran el carácter de un jefe de Estado que sabe defender los intereses de nuestro querido México de una manera constructiva. Le envío un cordial saludo, y afectuoso y respetuoso abrazo". ${ }^{76}$ Otras expresiones de los grandes empresarios tuvieron el mismo sentido. De cualquier forma, el curso que tome la política petrolera "nacionalista" del nuevo gobierno y la controvertida construcción de la refinería de Dos Bocas serán temas importantes para las relaciones con los empresarios.

Contrastes en las apreciaciones empresariales sobre el desempeño del gobierno de Enrique Peña Nieto

Las posiciones de los empresarios ante el desempeño del gobierno de Enrique Peña Nieto y las relaciones con su gobierno son diferenciadas y dependen de las actividades económicas a las que se dedican, de su tamaño, de la región en la que se ubican, de la generación a la que pertenecen, de sus preferencias políticas y de muchos otros factores.

76 Stephanie Cuevas, "Baillères felicita a López Obrador por carta a Trump sobre aranceles”, El Financiero, 3 de junio de 2019. 
Si se contrasta el caso de los pequeños y de los grandes empresarios podremos observar algunas diferencias. En relación con las micro-, pequeñas y medianas empresas, Peña Nieto contrajo tres compromisos de campaña que firmó ante notario; al inicio de su mandato ordenó que se implementaran tres medidas que facilitaran la participación de estas empresas en las compras de la administración pública federal, para promocionarlas como proveedoras de empleo: 1. Otorgar créditos de la banca de desarrollo para mujeres emprendedoras. 2. Crear el Instituto Nacional del Emprendedor para el Crédito, Formación y Capacitación de los Emprendedores (Inadem), con el objetivo de instrumentar, ejecutar y coordinar la política nacional de apoyo incluyente a emprendedores y a las micro-, pequeñas y medianas empresas, apoyando su capacidad de innovación, competitividad y proyección en los mercados nacional e internacional. 3. Crear un fondo de 1000 millones de pesos anuales, con créditos blandos y programas de apoyo concurrentes para permitir a las Mipymes incorporar tecnologías de la información y comunicación en sus procesos. El propósito de este fondo sería incentivar el crecimiento económico nacional, regional y sectorial mediante el fomento a la productividad e innovación en las Mipymes ubicadas en sectores estratégicos.

Respecto a esta última promesa, representantes de pequeñas empresas consideran que no se cumplió porque los recursos destinados al fortalecimiento de las Mipymes fueron decreciendo año con año y cayeron hasta en 50\%. El presidente de la Asociación Latinoamericana de Micros, Pequeños y Medianos Empresarios (Alampyme), Alejandro Salcedo, declaró que en el sexenio de Peña Nieto "las micro, pequeñas y medianas empresas tuvimos muchos problemas. Hubo cierres de negocios por la cuestión económica, la inseguridad y por falta de créditos y de apoyos reales. Nosotros calculamos que durante todo este sexenio cerraron más de 350000 pequeños negocios y eso dejó un déficit de 
más de un millón de empleos directos". ${ }^{77}$ El mismo empresario denunció que los apoyos del gobierno de Peña Nieto a través del Inadem sólo beneficiaron a un pequeño grupo de negocios y que la mayoría de los recursos se canalizaron más a las empresas medianas, en lugar de las micro- y pequeñas. En sus palabras: "Realmente fue un programa que hizo el presidente Peña Nieto sólo para beneficiar a sus cuates empresarios". 78

Los principales problemas que los dirigentes de las pequeñas y medianas empresas observaron durante el sexenio fueron: la falta de difusión de los apoyos que el gobierno otorga a los empresarios a través de Inadem; la creación de programas que terminan siendo instrumentos políticos; los apoyos del gobierno, que son difíciles de conseguir y se necesitan casi padrinos para obtenerlos; las reglas de operación de los programas federales, que parecen estar hechas para desalentar las solicitudes; el sector de las Pymes, que no puede acceder a los contratos que otorga el gobierno, debido a los requisitos que deben presentar, los cuales sólo las grandes corporaciones cumplen; aunque las licitaciones estén abiertas a todas las empresas, para una Pyme es más difícil cumplir con los trámites e incluso se advierte que algunos servidores públicos transmiten información a las grandes empresas de manera ilegal; a los empresarios no se les involucra en políticas públicas, por lo que no se les toma en cuenta. ${ }^{79}$

77 "Micro, pequeñas y medianas empresas, olvidadas en el gobierno de EPN", Polemón, 11 de septiembre de 2018, https://polemon.mx/micropequenas-y-medianas-empresas-olvidadas-en-gobierno-de-epn (consulta del 9 de junio de 2019).

78 Loc. cit.

${ }^{79}$ Alejando Salcedo, presidente nacional de la Asociación Latinoamericana de Micros, Pequeños y Medianos Empresarios (Alampyme), calcula que durante este sexenio se han cerrado más de 350000 micro- y pequeñas empresas por falta de créditos, de apoyos de programas públicos, por la sobrerregulación que existe en la apertura de negocios y por el tema de la inseguridad con el cobro y derecho de piso. Véase "Con Peña Nieto cerraron 350 mil empresas chicas; se dedicó a las grandes, acusan", Vanguardia.mx, 2 de septiembre de 2018, https://vanguardia. 
Uno de estos dirigentes considera que si se destinara un $20 \%$ de las compras del gobierno a la planta productiva local, se tendría una reactivación muy importante. También hay empresarios, como Alfredo Neme Martínez, presidente del Consejo Nacional de la Alimentación, que consideran que algunos grandes problemas son la corrupción y la burocracia en los distintos trámites que deben realizar las empresas para cumplir con la normatividad. Para la Alampyme, en el sexenio de Peña Nieto la participación de las Pymes en los contratos del gobierno fue escasa o casi nula. ${ }^{80}$

En el otro lado del espectro de las organizaciones, para el $\mathrm{CCE},{ }^{81}$ el sexenio de Peña Nieto dejó un legado de activos que es importante preservar. ${ }^{82}$ Según su presidente, Juan Pablo Castañón, entre los principales logros estuvieron las reformas estructurales, destacadamente la apertura de los mercados energético y de telecomunicaciones. En cuanto a la reforma a la Ley Federal del Trabajo, se reconoce una mejora en la eficiencia de la regulación laboral, así como haber incrementado el ingreso de los trabajadores, elevando el poder adquisitivo del salario en $17 \%$ con respecto a 2012; en materia de competencia, desde su perspectiva, la economía se benefició

com.mx/articulo/con-pena-nieto-cerraron-350-mil-empresas-chicas-sededico-las-grandes-acusan (consulta del 21 de febrero de 2020).

80 "Para la Alampyme, que integra a más de 17 mil micro y pequeños empresarios del país, las grandes firmas utilizan todos los recursos para favorecerse de los mecanismos del SAT, que de 2007 a 2015 perdonó a 7 mil 885 personas y empresas un monto de 172 mil 335 millones de pesos". Véase Guadalupe Fuentes López, "Peña y Calderón perdonaron de impuestos a los multimillonarios, y a menos del 1\% de los chiquitos", Sin Embargo, 22 de octubre de 2019, https://www.sinembargo.mx/22-102019/3662042

${ }^{81}$ Para un acercamiento al Consejo Coordinador Empresarial, puede consultarse Matilde Luna y Ricardo Tirado, El Consejo Coordinador Empresarial. Una radiografia, Proyecto Organizaciones Empresariales en México, Cuaderno de Investigación 1, México, IIs / FCPys, UnAM, 1992.

82 "Peña Nieto deja México estable económicamente: empresarios", Forbes, 25 de noviembre de 2018, https://www.forbes.com.mx/empresa rios-destacan-que-pena-nieto-deja-mexico-estable-en-economia/ (consulta del 9 de junio de 2019). 
de un organismo regulador más independiente y fuerte. También se reconoce que se lograron reducir las barreras de entrada y los costos de transacción, sobre todo para miles de pequeños y medianos empresarios.

Un logro muy apreciado por estos empresarios es haber dejado un país estable en materia económica, con inflación promedio controlada y también estable, y un equilibrio fiscal responsable, lo que permitió el crecimiento de la economía durante 35 trimestres consecutivos.

Sin duda, el cce se sintió cercano al gobierno de Peña Nieto, ya que en varias de las evaluaciones públicas del sexenio se emplea el plural de autoría para referirse a los logros, por ejemplo: "Gracias al trabajo del gobierno, legisladores y empresarios, sumamos esfuerzos para que México hoy tenga un mejor clima de negocios, con menores trámites y reglas claras para los inversionistas y emprendedores". ${ }^{83}$

En el contexto de las posturas de otros países y actores que cuestionan el libre comercio y establecen barreras proteccionistas, el ccE recalcó su beneplácito por que el gobierno de Peña Nieto reafirmara su apuesta por un modelo de apertura económica, lo que habría quedado de manifiesto con la renovación y modernización de los acuerdos comerciales con el mundo, como la firma del Tratado Integral y Progresivo de Asociación Transpacífico (СPTPP, por sus siglas en inglés), el TLCUEM y el T-MEC, además de fortalecer los mecanismos de cooperación con la Alianza del Pacífico.

Aunque, en su conjunto, la entidad que representa a todas las organizaciones empresariales reconoce muchos logros del gobierno de Peña Nieto y su balance general es positivo, no deja de señalar también sus límites y muchos problemas. ${ }^{84}$ Para empezar, la persistencia del bajo creci-

${ }^{83}$ Consejo Coordinador Empresarial, CCE, "Un balance de cara a la transmisión de poderes en el ejecutivo" (comunicado), México, CCE, 25 de noviembre de 2018, https://www.cce.org.mx/un-balance-de-cara-a-latransmision-de-poderes-en-el-ejecutivo/

${ }^{84}$ Loc. cit. 
miento de la economía y las diferencias regionales y sectoriales que dividen a los mexicanos, sobre todo en el sur y sureste, donde esta organización cúpula admite que la pobreza sigue manifestando niveles intolerables. También reconoce que a pesar de los esfuerzos, el país no ha logrado brindar oportunidades de empleo y desarrollo para millones de mexicanos. Sin embargo, en ningún momento el CCE alude al tema de las desigualdades socioeconómicas. Para esta organización cúpula, acelerar un crecimiento económico incluyente es uno de los mayores retos del futuro, ya que, desde su perspectiva, es el empleo el que podrá sacar a las personas de la pobreza. Y ese crecimiento sólo podrá darse si se logra fomentar la inversión y el desarrollo de las empresas, puesto que, desde su visión, son las únicas que generan riqueza y empleo de manera sustentable.

Un tema importante que apareció durante el sexenio de Peña Nieto fue un conflicto de interés que involucró al presidente y a un grupo empresarial de la industria de la construcción: el caso de la "Casa Blanca". Sobre este acontecimiento no se conoce la posición de las organizaciones empresariales, pero es de suponer que influyó en su percepción y distanciamiento del presidente, sobre todo de la Coparmex. ${ }^{85}$ En México es conocido históricamente que una de las mayores fuentes de corrupción entre algunos miembros de la clase política y ciertos miembros del sector empresarial es el otorgamiento de concesiones y contratos a empresas a cambio de compensaciones económicas.

${ }^{85}$ En un programa radiofónico, el presidente de la Coparmex, Gustavo dee Hoyos, declaró que "si a Peña Nieto lo marcó 'la Casa Blanca', Texcoco marcará el sexenio del presidente López Obrador". Véase "Si a EPN lo marcó la casa blanca, Texcoco marcará el sexenio de AMLo: Coparmex", 30 de octubre de 2018, http://diariotiempo.mx/economia/ si-a-epn-lo-marco-la-casa-blanca-texcoco-marcara-el-sexenio-de-amlo-co parmex/ 
La periodista Carmen Aristegui y su equipo hicieron pública, el 9 de noviembre de 2014, una investigación en la que mostraron que el presidente Enrique Peña Nieto incurrió en un conflicto de interés porque su esposa, Angélica Rivera, adquirió una residencia valuada en siete millones de dólares a una empresa del Grupo Higa, que había ganado contratos de obras cuando Peña Nieto fue gobernador del Estado de México (2005-2011) y que durante su gestión presidencial obtuvo, junto a otros consorcios, la licitación del tren rápido México-Querétaro. ${ }^{86}$ En respuesta, Angélica Rivera hizo público un video en el que expresó que la compra había sido realizada con sus ahorros como actriz de Televisa y que vendería el inmueble para evitar que fuera pretexto para ofender y difamar a su familia. A su vez, la reacción del presidente fue cancelar la licitación de la construcción del tren rápido (en la que participaría el Grupo Higa y una empresa china) y ordenar una investigación a cargo del titular de la Secretaría de la Función Pública (SFP), quien concluyó que no había conflicto de interés porque la casa había sido adquirida por Angélica Rivera con su patrimonio exclusivo proveniente de su carrera como actriz. Poco después de la denuncia de Aristegui, el diario The Wall Street Journal publicó un artículo en que vinculaba a Luis Videgaray, secretario de Hacienda del gobierno de Peña Nieto, con la compra de una casa en Malinalco a la empresa Bienes Raíces H\&G, de Juan Armando Hinojosa, propietario del Grupo Higa. Videgaray respondió que la compra era legal y que no había habido conflicto de interés porque la transacción la había realizado cuando aún no tenía un cargo público. Aunque ambos casos fueron legalmente desestimados, influyeron, junto con otros factores, en el declive progresivo de la imagen del presidente entre muchos empresarios y, en general, entre los ciudadanos, y pudo haber influido, habría que comprobarlo, en que Luis

86 "La casa blanca de Enrique Peña Nieto (investigación especial)", Aristegui Noticias, 9 de noviembre de 2014, https://aristeguinoticias. com/0911/mexico/la-casa-blanca-de-enrique-pena-nieto/ 
Videgaray no fuera candidato del PRI a la presidencia de la República.

También el affaire Odebrecht ${ }^{87}$ tuvo un fuerte impacto en Peña Nieto y en miembros de su equipo, y contribuyó a deteriorar su imagen en la opinión pública y en una parte de los empresarios. Emilio Lozoya, uno de sus colaboradores cercanos, quien participó como coordinador de asuntos internacionales de su campaña electoral y después ocupó el cargo de director general de Pemex, según diversas investigaciones -entre ellas, la de Mexicanos contra la Corrupción y la Impunidad, impulsada por un grupo de empresarios-, habría recibido sobornos de Odebrecht y adquirido para él y su familia propiedades en la Ciudad de México, Ixtapa y Ginebra. Hasta diciembre de 2019, Lozoya estaba prófugo, fue inhabilitado por diez años para ejercer la función pública y sus cuentas fueron congeladas. También se abrió una investigación sobre supuestos delitos en la campaña presidencial 2011-2012 del entonces candidato Peña Nieto; sin embargo, la investigación fue archivada porque la Fiscalía Especializada en Delitos Electorales declaró: "[...] determino formalmente que no hay delito que perseguir $[\ldots]$, ya que los probables ilícitos han prescrito", pero se mantendrá abierta la indagatoria sobre posibles delitos electorales cometidos a partir de 2014. ${ }^{88}$

Según la SFP, la constructora brasileña Odebrecht incurrió en presuntos actos de corrupción para obtener ventajas en obras que le fueron adjudicadas de forma directa en la

${ }^{87}$ La trama de corrupción consistía en la entrega de sobornos de Odebrecht o subsidiarias de la constructora brasileña, para obtener contratos en el gobierno. Véase Mexicanos Contra la Corrupción y la Impunidad, “¿Quién es Sergio Moro?”, YouTube, 31 de julio de 2017, https:// www.youtube.com/watch?v=11_K1tezcIg

88 "Cierran investigación sobre financiación de Odebrecht a campaña de Peña Nieto", EFE, 20 de junio de 2019, https://www.efe.com/efe/ america/mexico/cierran-investigacion-sobre-financiacion-de-odebrechta-campana-pena-nieto/50000545-4005600 (consulta del 6 de diciembre de 2019). 
refinería de Tula, Hidalgo. En estos sobornos está implicado -y fue detenido- el empresario siderúrgico Alonso Ancira, presidente de Altos Hornos de México, quien vendió en 2014 con sobreprecio una empresa de fertilizantes a Pemex. ${ }^{89}$ Altos Hornos estaría detrás de sobornos millonarios pagados por Odebrecht a políticos mexicanos.

Entre las principales limitaciones que el CCE observa durante este sexenio están los niveles récord de inseguridad y violencia, y la debilidad del Estado de derecho que ha vivido México, por lo que Castañón advierte que "México no puede crecer económicamente si el clima de negocios está enrarecido por la delincuencia y la impunidad”. El 20 de enero de 2015, el cCE publicó un desplegado dirigido a los representantes de los tres poderes de la Unión en los tres órdenes de gobierno que dice: "Condenamos enérgicamente las agresiones en contra del sector empresarial y sus organizaciones, así como los bloqueos de carreteras y casetas que han sucedido en varias zonas del país". ${ }^{90}$ También se hace notar el contraste entre, por una parte, la existencia de un ambiente de libertad de expresión y libertades individuales que abonarían a la madurez de la democracia mexicana, y por la otra, la dificultad de las instituciones para hacer cumplir el marco legal, lo que habría provocado una profunda crisis de confianza en la autoridad y las instituciones. También se enfatizan los problemas de la impunidad, la corrupción, así como la dificultad para hacer prevalecer la ley, lo que, según el CCE, habría desembocado en frenos para el desarrollo de las empresas y el emprendimiento de los jóvenes.

89 Jon Martín Cullell y Lucía Bohórquez, "México ordena el arresto del exdirector de Pemex y logra la captura de un empresario por el 'caso Odebrecht' ", El País, 29 de mayo de 2019, https://elpais.com/ internacional/2019/05/28/mexico/1559055206_285704.html (consulta del 3 de diciembre de 2019).

90 "Agresiones en contra del sector empresarial y sus organizaciones", Consejo Coordinador Empresarial, 20 de enero de 2015, https://www.cce. org.mx/a-los-representantes-de-los-tres-poderes-de-la-union-en-los-tresordenes-de-gobierno-2/ 
El organismo empresarial planteó la necesidad crear un sistema educativo que permitiera desplegar las habilidades hacia el futuro, sobre todo, en el campo laboral. También abogó por la generación de conocimiento a través del fomento a la investigación y el desarrollo tecnológico en México, indicando que el país invierte sólo el $0.6 \%$ del pib en este sector, mientras que el promedio de los países de la OCDE es de $2.5 \% .{ }^{91}$ Ese conocimiento derivado de la investigación científica, además, necesitaría estar más vinculado con la empresa, para crear más empleos mejor remunerados. Sin embargo, el organismo no señaló la responsabilidad que tiene no sólo el Estado, sino también la iniciativa privada, en la inversión en investigación y desarrollo. Es sabido el poco interés que ha habido históricamente en el sector empresarial mexicano en la inversión en investigación. Al respecto, la directora del Consejo Nacional de Ciencia y Tecnología (Conacyt) ha informado que durante el sexenio de Peña Nieto esa institución entregó a la iniciativa privada 35000 millones de pesos, casi la mitad de su presupuesto $(48 \%)$, lo que generó un déficit de 21269 millones de pesos. ${ }^{92}$

El CCE también reconoció la falta de más inversión en infraestructura, ya que según el Índice de Competitividad Global 2017-2018, citado por el organismo cúpula, México descendió y se ubicaba en el lugar 62 de 137 economías en cuanto a competitividad en infraestructura, lo que se habría traducido en altos costos logísticos para transportar las mercancías; si el promedio de éstos para los países miembros de la OCDE era de 9\% del PIB, en México se elevaban al 22.7\%.

Según el diagnóstico que hizo el ccE de la situación que vivía México al final del gobierno de Peña Nieto, el desafío consistía en conseguir un mayor crecimiento económico que, además, fuera incluyente, a través de las grandes inversiones y los programas que la sociedad esperaría, con la exi-

91 "Peña Nieto deja...", art. cit.

${ }^{92}$ Sara Pantoja, "En sexenio de Peña, el Conacyt transfirió el 48\% de sus recursos a la IP: Álvarez-Buylla”, Proceso, 27 de junio de 2019. 
gencia de mantener finanzas públicas sanas y la estabilidad económica, que brindaran confianza y certidumbre para la inversión y la generación de empleos. El Consejo consideró que si el entrante gobierno de López Obrador lograra esto, el bienestar podría elevarse y la desigualdad reducirse y, por lo tanto, se podría seguir construyendo un mejor futuro para todos los ciudadanos.

Una gran pregunta para el CCE y, por extensión, para gran parte de las organizaciones que representan los intereses de las empresas medianas y grandes, en el marco de la contienda y el desenlace electoral de 2018, era sobre la continuidad y el cambio. ¿Qué posturas asumir ante la candidatura de un gobierno autoproclamado de izquierda? ¿Qué hacer si López Obrador ganara las elecciones? Ése es el tema del último apartado. Aunque se refiere al presidente actual, es pertinente incluirlo en el balance del sexenio de Peña Nieto porque conforme avanzó su sexenio y sobre todo el último año, la presencia del candidato de Juntos Haremos Historia ocupó gran parte del escenario político y social e influyó en las conductas de los empresarios.

Los empresarios ante Andrés Manuel López Obrador DURANTE SU CAMPAÑA Y DESPUÉS DE SU TRIUNFO ELECTORAL

En el ámbito de la política, los empresarios no son homogéneos ni tienen una postura unificada. Sin embargo, puede considerarse que la mayoría de los medianos y grandes, que son los que están más organizados y mejor representados a través de sus organizaciones, han tenido una clara preferencia por el PRI y el PAN, y han sido contrarios a López Obrador, tanto cuando militó en el PRD como en el Movimiento de Regeneración Nacional (Morena), mientras que sus principales simpatizantes en la iniciativa privada están entre los pequeños empresarios.

López Obrador designó a Alfonso Romo, un conocido y controvertido empresario de Monterrey, como coordinador 
de su proyecto de nación. Romo fue un valioso puente para que el candidato morenista se acercara no sólo al sector privado nacional e internacional, sobre todo con el del norte del país, sino también con una parte del electorado. Primero, porque es un hombre de negocios experimentado y emprendedor que habla el lenguaje de los empresarios; ha sido dueño de Cigarrera La Moderna, Pulsar Internacional (seguros, biotecnología y producción de semillas) y Savia. Segundo, porque ha tenido vínculos familiares con las grandes familias de empresarios de Monterrey, entre ellas, los Garza Sada (sin que hayan faltado también algunos enfrentamientos) y ha tenido vínculos de amistad con una parte de la clase política nacional. Tercero, porque con un lenguaje convincente ayudó a López Obrador a tranquilizar a una parte del electorado, preocupado por algunas presiones que miembros más radicales de Morena ejercen sobre el líder. Cuarto, porque cuenta con experiencia en la política partidaria, ya que participó en la campaña de Vicente Fox por la presidencia de la República, bajo las siglas del PAN, en 2000. Finalmente, porque ha mostrado sensibilidad y compromiso social a través del apoyo a proyectos culturales, educativos, sociales y ecológicos en el sur de México, y en ese sentido muestra que el proyecto económico de López Obrador busca vínculos entre las empresas, la sociedad y el medio ambiente. Ésa fue la función primordial que Romo desarrolló en esa etapa y, por esos motivos, poco antes del cierre de campaña, en Monterrey, López Obrador declaró que si ganaba las elecciones designaría a Alfonso Romo coordinador de la oficina de la presidencia de la República.

Si tomamos en consideración solamente a los empresarios organizados, desde antes de que arrancara la contienda electoral empezaron a manifestar públicamente sus preferencias electorales. Algunos de los más reconocidos criticaron abiertamente al presidente Enrique Peña Nieto en temas relacionados con la corrupción, la delincuencia y los derechos humanos. Sin embargo, eso no impidió que respaldaran a quien se vislumbraba como el favorito del presidente: 
José Antonio Meade, el secretario de Hacienda, quien acababa de renunciar para buscar la nominación del PRI. Faltaban siete meses para las elecciones y desde la perspectiva de algunos grandes empresarios, Meade parecía ser la mejor opción para enfrentar a Andrés Manuel López Obrador, quien a menudo había cuestionado varias de las reformas impulsadas por Peña Nieto caras a ellos, y había declarado que podría revertir algunas.

La relación de López Obrador con algunos de los grandes empresarios ha sido de confrontación desde las campañas presidenciales de 2006 y 2012. Él mismo les atribuye, en parte, que no lograra ganar los comicios y llegar a la presidencia, por haber utilizado su poder y su dinero en las campañas electorales en su contra, utilizando medios ilegales e ilegítimos.

En esta tercera vez en que contendió López Obrador, los grandes empresarios empezaron a manifestar sus preferencias. Según la prensa, Claudio X. González Laporte, de Kimberly-Clark de México, y uno de los hombres de negocios más influyentes en la política desde el ámbito empresarial, dijo que López Obrador debía ser derrotado en 2018 y que Meade era uno de los potenciales candidatos más fuertes para el PRI. ${ }^{93}$ Por su parte, Juan Pablo Castañón, presidente del CCE, declaraba: "Meade es un hombre inteligente, preparado, sencillo, que tiene una visión clara sobre el México del futuro y con quien hemos podido construir está visión compartida. Estamos seguros de que, con él y su equipo de trabajo, la plataforma del partido que lo postula, podemos analizar los retos del sector empresarial". ${ }^{44}$ Según Enrique Coppel

${ }^{93}$ Andrea Navarro, "Líderes empresariales parecen respaldar a Meade", El Financiero, 29 de noviembre de 2017, https://www.elfinanciero. com.mx/nacional/lideres-empresariales-parecen-respaldar-a-meade, (consulta del 13 de junio de 2019).

${ }^{94}$ Rocío Méndez, "Meade tiene una visión clara sobre el México del futuro: CCE", MVs Noticias, 28 de noviembre de 2017, https://mvsnoticias. $\mathrm{com} /$ noticias/economia/meade-tiene-una-vision-clara-sobre-el-mexicodel-futuro-cce-311/ 
Luken, empresario del sector comercial y bancario, Meade sería el presidente "más capaz" que México podría tener en años. Por su parte, Manuel Herrera, presidente de la Concamin, dijo en un tuit: “A mi estimado @JoseAMeadeK, le deseo todo el éxito. Siempre, desde todos sus encargos, con profesionalismo, ha sido amigo de los industriales. Mi agradecimiento por la disposición a trabajarcon@CONCAMIN". ${ }^{95}$

Sin embargo, el entusiasmo y las preferencias de muchos empresarios por Meade declinaron en el curso de la campaña. Después del primer debate presidencial del 22 de abril de 2018, realizado en el Palacio de Minería, y ante el estancamiento de Meade en los sondeos de opinión sobre las preferencias electorales, los grandes empresarios lo abandonarían y optarían por el panista Ricardo Anaya, postulado por la coalición Por México al Frente, que era su segunda preferencia y, en ese momento, el único que podría remontar la ventaja del puntero. Según algunos analistas, quienes impulsaron esta decisión fueron los mismos empresarios del GMN que habían supuestamente visitado al presidente en Los Pinos para pedirle que dejara de utilizar las instituciones (la PGR, en particular, que lo había acusado de lavado de dinero) contra el candidato Anaya. El presidente y su vocero negaron que esa reunión hubiera ocurrido. ${ }^{96}$ Sea como fuere, la propaganda contra Anaya tuvo severas consecuencias en las en-

95 Manuel Herrera Vega (@ManuelHerreraV), “A mi estimado @JoseAMeadeK..." (mensaje de Twitter), 27 de noviembre de 2016 (consulta del 13 de junio de 2019).

96 "Nadie negocia conmigo. Candidatos y sus campañas corren en otro camino: EPN", Expansión Política, 2 de mayo de 2018, https:/ / politica. expansion.mx/presidencia/2018/05/02/nadie-negocia-conmigo-candidatos-y-sus-campanas-corren-en-otro-camino-epn (consulta del 14 de junio de 2019). Tanto el presidente Peña Nieto como el vocero del gobierno, negaron -como lo declaró López Obrador- que haya habido una reunión en la que habrían estado Alberto Baillères, Germán Larrea, Eduardo Tricio, Alejandro Ramírez, Claudio X. González, Diego Fernández de Cevallos y el expresidente Vicente Fox, donde Anaya habría pedido su apoyo para convencer a Peña de apoyar su candidatura. 
cuestas electorales. ${ }^{97}$ Sin embargo, era claro el conflicto entre el presidente de México y Anaya (este último amenazó al presidente Peña Nieto con meterlo a la cárcel si descubría que también él estuvo involucrado en algún acto de corrupción grave). Además, los golpes mediáticos que recibía el candidato panista no hacían crecer la candidatura de Meade pero sí la de López Obrador. Los acontecimientos hacían pensar que los empresarios reclamaban la forma en que el gobierno intervenía en la candidatura en favor de Meade y en contra de Anaya. Un empresario lo expresaría así: "No es la persona (Meade); a él lo respetamos y consideramos que es un funcionario impecable; es lo que está detrás de él". ${ }^{98}$

Después de una reunión de Anaya con el cmN, los empresarios concluyeron que era "un joven brillante, con talento y buenas propuestas", aunque reconocían que le faltaba experiencia política. ${ }^{99}$

Primero en reuniones privadas y después de manera abierta, los empresarios empezaron a manifestar tanto sus preferencias y apoyos a los candidatos de las coaliciones del PRI y del PAn, cuanto su rechazo al líder de Morena. Eduardo Tricio, presidente del Grupo Lala, y vicepresidente del CMN, confesó lo que muchos otros estarían pensando: "Me da miedo que se paren o se quieran parar proyectos como el aeropuerto". Baillères fue más explícito: "Voten por el candidato que tenga la mayor probabilidad de vencer a Andrés Manuel López Obrador", mientras que Larrea pidió: "Salgamos a votar

${ }^{97}$ En realidad, la denuncia formal fue presentada por el senador del PAN Ernesto Cordero. "Acusa Ernesto Cordero a Ricardo Anaya, en la PGR, de lavado de dinero", Aristegui Noticias, 11 de junio de 2018, https:// aristeguinoticias.com/1106/mexico/acusa-ernesto-cordero-a-ricardoanaya-en-la-pgr-de-lavado-de-dinero/

${ }^{98}$ Mario Maldonado, "Cuando los empresarios cambiaron a Meade por Anaya”, El Universal, 20 de junio de 2018, https://www.eluniversal. com.mx/columna/mario-maldonado/cartera/cuando-los-empresarioscambiaron-meade-por-anaya (consulta del 14 de junio de 2019).

${ }^{99}$ Mario Maldonado, "Empresarios van con Anaya si Meade no levanta”, El Universal, 23 de abril de 2018. 
libremente, con inteligencia y no con el enojo que hoy todos compartimos". 100

A diferencia de la contienda de 2006, en la que los empresarios difundieron spots que pregonaban que elegir una opción política distinta al candidato del PAN era retroceder en México, en la de 2018 algunos de ellos prefirieron dirigir mensajes directamente a sus empleados, sugiriéndoles emitir su voto en el sentido que conviniera a su lugar de trabajo e insinuando que el triunfo de la "opción populista" representaba un riesgo para sus fuentes de empleo.

Germán Larrea, del Grupo México, mandó, el 25 de mayo de 2018, una carta firmada a sus empleados, colaboradores y accionistas, para advertirles de los riesgos ante el triunfo de un "modelo populista". En ella, niega las acusaciones de "compadrazgo y corrupción" lanzadas por el candidato de Morena y advierte que como empresario cree "en un modelo capitalista de libre mercado con un alto contenido de responsabilidad social, como único modelo viable para generar bienestar y crecimiento". Señala que recientemente había "escuchado con preocupación propuestas de estatización de empresas, derogación de reformas energética y educativa, entre otras ideas que significarían un retroceso de décadas y el regreso a un modelo económico que está más que probado que no ha funcionado en varios países. Venezuela, Argentina, Cuba, la extinta Unión Soviética, entre otros, son testigos de ello". Añade que "este modelo económico afectaría el desarrollo y bienestar del país, de la economía familiar y de las empresas mexicanas". Y advierte que "si este modelo económico populista, en donde todo supuestamente pertenece y proviene del Estado, y en el que se ofrece regalar sin trabajar, se llegara a imponer en México, se desincentivarían las inversiones afectando gravemente a los empleados y a la economía". Enfatiza que "es indispensable un clima de seguridad para continuar con las importantes inversiones que venimos desarrollando en los diferentes pro-

${ }^{100}$ Loc. cit. 
yectos mineros, de transporte e infraestructura". Finaliza diciendo: "analicemos las propuestas de los candidatos y entendamos los beneficios y consecuencias de cada uno para poder emitir un voto libre, responsable, informado y útil, que sea para tener un mejor México [...] Cuidemos todos a nuestra empresa que es nuestra fuente de trabajo, sustento familiar y bienestar".

José Elizondo, presidente de Vasconia, hizo circular un video en que declara que los empresarios deben estar preparados por "si desafortunadamente, el 1 de julio gana, la opción populista, con todas sus consecuencias". ${ }^{101}$ Héctor Hernández Pons, director del Grupo Herdez, difundió una carta para alertar sobre los riesgos de una devaluación: "Seremos más cautelosos en nuestras inversiones, limitándonos, por lo pronto, a la protección y conservación de nuestros activos". ${ }^{102}$

Eloy Vallina, presidente del Grupo Chihuahua, declaró que pesaba en su ánimo "no querer que el país sufra una regresión a estos tiempos de las presidencias imperiales que llevadas por la iluminación mesiánica y la impunidad autoritaria se apropian del patrimonio ya generado por otros para después repartirlo a su antojo". ${ }^{103}$

En relación con Alberto Baillères, según lo dio a conocer El Financiero, directivos de El Palacio de Hierro citaron al personal en el comedor de la sucursal Perisur para una reunión obligatoria. "En los siguientes 40 minutos, el mensaje fue repetido una y otra vez, de acuerdo con empleados que estuvieron presentes esa noche: Voten por el candidato que tenga la mayor probabilidad de vencer a López Obrador; es la mejor oportunidad que tenemos de preservar el sistema económico que nos permite emplearlos", habría declarado uno de los jefes de la tienda.

101 Octavio Ortega, “¿Quiénes son los empresarios que piden no votar por AmLo?”, La Nación, 31 de mayo de 2018.

102 “Alerta Herdez por futuro difícil”, NNC.mx, 27 de mayo de 2018.

103 "Las diez principales frases de Eloy Vallina", Tiempo la noticia digital, 25 de mayo de 2018. 
Andrés Conesa, director de Aeroméxico, en una carta que se hizo pública, declara: "en estos últimos tiempos he percibido [...] un profundo descontento y malestar [...] relacionados [con] la corrupción, impunidad y los aumentos en los niveles de inseguridad [...] pero [...] estoy convencido que no hay fórmulas mágicas para resolver estos problemas [...], y que no debemos tomar decisiones tan importantes, como por quién votar, enojados. Debemos tomarlas con la cabeza fría y de forma razonada". ${ }^{104}$

A la mitad de las elecciones, el vocero de la campaña de Meade, Javier Lozano, aseguró que el sector empresarial estaba presionando fuertemente al candidato del PRI para que declinara en favor Anaya con el objetivo de frenar a López Obrador. Y "ese no es el camino. No viene al caso cuando estamos en el primer tercio de las elecciones", expresó Lozano en entrevista con Grupo Fórmula. También Jorge Camacho, vocero de la campaña de la candidata independiente Margarita Zavala, reconocería que existían esas presiones de los empresarios. ${ }^{105}$

De campaña en Zongolica, Veracruz, López Obrador dedicó gran parte del 1 de mayo de 2018 al tema de los empresarios y a la acción política de éstos en su contra y a favor de Anaya. Su boletín de campaña de ese día registra que "pidió a Ricardo Anaya que aclare si tuvo una reunión con empresarios, donde les pidió que lo apoyaran para convencer a Enrique Peña Nieto que la unidad es la única manera de ganar a López Obrador y que apoye la candidatura del panista a la Presidencia de México". Alertó que empresarios como Alberto Baillères, Germán Larrea, Eduardo Tricio, Alejandro

104 Loc. cit.

105 "Lozano: Empresarios presionan para que Meade y Margarita declinen por Anaya", Nación 321, 1 de mayo de 2019, https://www.nacion321. com/elecciones/lozano-empresarios-estan-presionando-para-que-meadey-margarita-declinen (consulta del 14 de junio de 2019); "Empresarios niegan presión para que se unan Meade y Anaya”, El Financiero, 2 de mayo de 2019, https:/ / www.elfinanciero.com.mx/elecciones-2018/los-empresariosno-tenemos-candidato-ni-partido-cce (consulta del 14 de junio de 2018). 
Ramírez, Claudio X. González, así como los panistas Diego Fernández de Cevallos y Vicente Fox se habían reunido un mes o mes y medio antes con Ricardo Anaya para que moderara su amenaza de meter a la cárcel a Peña Nieto.

También en Zongolica, López Obrador hizo un pronunciamiento de alto impacto al declarar: "es cierto que hay un grupo de empresarios -traficantes de influencias- que presionan mucho para que se unan los otros candidatos en contra mía”. Según el mencionado boletín de campaña, López Obrador comentó que "los integrantes de la mafia del poder están divididos" y les mandó decir "que no se preocupen, que no es su fuerte la venganza, que van a cambiar las cosas, lo único que puede ser que no les guste es que ya no van a seguir robando y ya no van a tener el privilegio de mandar". También diría públicamente: "No es nada más el que quieren seguir robando, es que quieren el privilegio de mandar, porque son muy vanidosos, pero yo los voy a tratar con mucho respeto, no voy a perseguir a nadie, va a haber respeto al Estado de derecho [...)], al margen de la ley nada, por encima de la ley nadie, va a haber legalidad, no habrá arbitrariedades". ${ }^{106}$

Estas declaraciones llevaron a su punto más alto la confrontación con los empresarios del CMN, quienes condenaron los "ataques personales" y las "descalificaciones infundadas" a través de un desplegado publicado en la prensa el 3 de mayo, titulado "Así no", en que "rechaza categóricamente las expresiones injuriosas y calumniosas", y advierte: "Condenamos que un candidato a la presidencia de la República recurra a ataques personales y a descalificaciones infundadas. Es preocupante que alguien que aspira a ser presidente de México denoste a quienes no comparten sus ideas". Después de declarar que "las empresas de este consejo emplean de manera directa a más de un mi-

106 "Llama AMLO a adversarios y mafia del poder que se preparen, porque ya es tiempo que haya democracia en México", boletín de campaña-042, 1 de mayo de 2018. 
llón y medio de jefes de familias mexicanas e invierten cada año miles de millones de dólares en nuestro país, lo cual contribuye al crecimiento de la economía, de la competitividad y del empleo", señala que "las condiciones de confianza y certeza jurídica son fundamentales para preservar y promover el ahorro, la inversión, el crecimiento económico y el empleo. La confianza se cultiva. No se dicta ni se obliga. Las expresiones y descalificaciones infundadas no ayudan a generarla. No es denigrando ni calumniando como se establece y fortalece una relación constructiva y de confianza con el sector productivo y empresarial de México". ${ }^{107}$

Ante este pronunciamiento, López Obrador dijo respetar sus posturas, pero insistió en que algunos miembros de ese grupo de empresarios le han hecho mucho daño al país: "Ellos son responsables de la tragedia nacional, en buena medida es el grupo que se opone a que haya un cambio en México porque les ha ido muy bien a ellos. No quieren dejar de robar", explicó a los representantes de los medios reunidos en la 59 Semana Nacional de la Radio y Televisión. ${ }^{108}$

Cinco días antes de que se realizara la elección presidencial, un grupo de empresarios manifestó su apoyo a Meade Kuribreña. Entre ellos estuvieron Marinela Servitje, del Grupo Bimbo; Arturo Elías Ayub, yerno de Carlos Slim y director de Alianzas Estratégicas de Telmex; Ernesto Torres Cantú, director general del Grupo Financiero Banamex; Juan Gallardo, presidente de Cultiba; Fernando Chico Pardo, presidente de Asur; Elías Cababie, presidente de Grupo GICSA; Edilberto Huesca, presidente de NRM Comunicaciones; Lino de Prado, presidente del Consejo de Administración de Zara México; Juan Ignacio Ávalos, presidente y fundador de Un

${ }^{107}$ Lilia González, "Cúpulas de la IP condenan expresiones de AMLO", El Economista, 3 de mayo de 2018, https://www.eleconomista.com.mx/ politica/Cupulas-de-la-IP-condenan-expresiones-de-AMLO-201805040021.html

108 "AMLO: 'Algunos de los que avalan el desplegado 'Así no' (CMN) han impedido la democracia del país' ”, Sin Embargo, 3 de mayo de 2018, https://www.sinembargo.mx/03-05-2018/3414571 
Kilo de Ayuda; Enrique Norten, fundador de TEN Arquitectos, y Raúl Ferráez, presidente ejecutivo de la revista Líderes Mexicanos. ${ }^{109}$

Ante el desenlace de las elecciones y los resultados tan favorables a López Obrador, el CMN tenía frente a sí la pregunta de qué hacer. Éste y los demás organismos que representan a los empresarios decidieron felicitar al triunfador o, al menos, reconocer el triunfo.

Alejandro Ramírez, propietario de Cinépolis, en nombre de los cerca de sesenta miembros del CMN, celebró que las elecciones se hubieran realizado en paz y tranquilidad, y expresó por escrito "su felicitación a Andrés Manuel López Obrador [...], ya que las tendencias electorales lo dan por ganador [...]. Asimismo, reitera su determinación [del CMN] de colaborar con su gobierno para que México tenga mayor crecimiento y genere más empleos en beneficio de todos $[\ldots] " .{ }^{110}$

El presidente del CCE, Juan Pablo Castañón, quien durante la campaña electoral manifestó sus diferencias con López Obrador, sin una palabra de felicitación para el virtual ganador, señaló: "Los empresarios tenemos plena confianza en México, en sus instituciones y en sus ciudadanos. Estableceremos un diálogo propositivo, respetuoso y de colaboración con todas las autoridades electas, y seguiremos trabajando, como siempre, para construir un país con oportunidades para todos". ${ }^{111}$ El líder empresarial agregó que, ante la división

109 "Magnates ‘arropan' a Meade y piden a sociedad razonar su voto", Proceso, 25 de junio de 2018; Ariadna García, "Empresarios cierran filas con Meade Kuribreña”, El Universal, 26 de junio de 2018.

110 Diego Martínez, "Consejo Mexicano de Negocios ofrece colaboración con AmLo para generar más empleos", Aristegui Noticias, 1 de julio de 2009, https://aristeguinoticias.com/0107/mexico/consejo-mexicano-denegocios-ofrece-colaboracion-con-amlo-para-generar-mas-empleos/ (consulta del 14 de junio de 2019).

${ }^{111}$ Juan Carlos Cruz Vargas, "Sin mencionar a AMLO, el CCE dice que entablará colaboración con las autoridades electas", Proceso, 1 de julio de 2018. 
observada a lo largo de las campañas, debía seguir la unidad de todos los mexicanos que, al final del día, tienen el mismo anhelo de construir un México con mejor futuro.

La Coparmex expresó su felicitación y manifestó: "El presidente de la República encontrará en la Coparmex un aliado para impulsar la lucha frontal contra la corrupción, que ha sido su oferta principal a lo largo de la campaña”. Gustavo de Hoyos, presidente de la Confederación, destacó que con la nueva administración "el reto es hacer unidad", y que, si se mantiene un clima de certidumbre, de estabilidad, "podemos anticipar que, en los próximos meses, en los próximos años, podemos continuar con una ruta de crecimiento en el cual el país siga brindando certidumbre”. Destacó que comenzaría una nueva era en la vida democrática del país, pero que defenderían la libertad de expresión y su postura respecto a temas prioritarios para el sector, como "la creación de una fiscalía general autónoma, independiente del gobierno federal, y continuar con la implementación de las reformas energética y educativa”. Respecto a los desencuentros entre los empresarios y López Obrador, declaró: "El respeto que exigimos del candidato por convicción, lo exigiremos por poder legal de quien será presidente de la República. En cualquier momento estaremos atentos para que si se da en el futuro cualquier descalificación o violación de derechos, ahí estará la Coparmex para hacer la representación”. ${ }^{112}$

José Manuel López Campos, presidente de la Confederación de Cámaras Nacionales de Comercio, Servicios y Turismo (Concanaco Servytur), declaró que esa organización apoyaría y trabajaría de la mano de las autoridades electas en los comicios del 1 de julio, durante los cuales se presentó la más numerosa participación de la ciudadanía, lo cual, añadió, fortalece la democracia mexicana. Expuso que debido a la gran participación de los electores en los comicios no quedaron espacios para sospechas de fraude que pudieran deslegitimar a las autoridades democráticamente electas. También

112 "Respalda Coparmex a AMLO”, Excélsior, 2 de julio de 2018. 
hizo "un llamado a las 255 cámaras de comercio que integran ese organismo a sumarse con planteamientos relevantes de los sectores que representan para que se incorporen, junto con nuestro programa presentado a los candidatos en campaña, a las propuestas para integrarse al Plan Nacional de Desarrollo del nuevo gobierno federal". ${ }^{113}$

La Concamin, a través de un comunicado de prensa de su presidente, Francisco Cervantes, señaló, entre otras ideas, que como "representante de 112 cámaras y asociaciones industriales, que juntas contribuyen con el 35\% del PIB, 8.4 millones de trabajadores que significan el $42 \%$ del empleo formal y el $90 \%$ de las exportaciones del país, felicita al licenciado Andrés Manuel López Obrador por el triunfo obtenido en los comicios y le expresa el compromiso de trabajar junto con su gobierno”. Señaló que los afiliados a la Concamin deseaban que los nuevos equilibrios políticos resultantes de esta elección produjeran mejores gobiernos, que respondan con eficacia a la demanda social de mayor seguridad, supresión de la corrupción, pleno Estado de derecho y progreso económico y social sin distinción de grupos o regiones. Enfatizó que la agenda del progreso nacional requiere del trabajo coordinado de empresarios, la comunidad académica y científica, la sociedad y el gobierno, por lo que procuraría, "a la brevedad posible, los necesarios acercamientos que nos permitan iniciar un diálogo constructivo", 114

La Asociación Mexicana de Instituciones de Seguros (AMIS), al reconocer el triunfo del candidato morenista, declaró en voz de su presidente, Manuel Escobedo: "Estaremos trabajando en conjunto con los tres órdenes de gobierno, en especial con Andrés Manuel López Obrador, para que, en co-

113 Viridiana Mendoza Escamilla, "Concanaco trabajará con autoridades que los mexicanos eligieron democráticamente”, Forbes, 1 de julio de 2019.

114 Eduardo de la Rosa, "Sector industrial felicita a AMLO por ganar comicios", Milenio, 1 de julio de 2018, https://www.milenio.com/negocios/sector-industrial-felicita-amlo-ganar-comicios (consulta del 15 de junio de 2019). 
laboración con los diferentes sectores, impulsemos estrategias y políticas públicas que promuevan la economía del país y así, llevar los beneficios del seguro a más mexicanos, y contribuir al bienestar de las familias". ${ }^{115}$

La Asociación de Bancos de México ( $\mathrm{ABM}$ ), en un pronunciamiento publicado el 2 de julio, declaró que la información dada a conocer por el INE señalaba una tendencia favorable a López Obrador. En este contexto, decía: "La AMB refrenda su compromiso de trabajar con quien los ciudadanos han decidido sea al próximo presidente de la República para el periodo 2018-2024, compromiso manifestado desde la convención bancaria celebrada en marzo pasado". ${ }^{116}$

El presidente del Consejo Nacional Agropecuario (CNA), Bosco de la Vega, felicitó a López Obrador, a quien ofreció trabajar hombro con hombro para seguir en la construcción de un campo ganador y alentó a este sector a superar las diferencias políticas y a trabajar en unidad con las nuevas autoridades del gobierno. ${ }^{117}$

\section{Cuadro 4}

Extracto de las declaraciones de las organizaciones del CCE ante el triunfo de Andrés Manuel López Obrador

- Elecciones con paz y tranquilidad: CMN

- Felicita a López Obrador: CMN

- Determina colaborar con su gobierno: CMN

- Plena confianza en México, sus instituciones y sus ciudadanos: $\mathrm{CCE}$

115 Israel Rodríguez, “AMIS expresa felicitación a AMLO”, La Jornada, 2 de julio de 2018, https:/ / www.jornada.com.mx/ultimas/2018/07/02/ amis-expresa-felicitacion-a-amlo-341.html (consulta del 15 de junio de 2019).

116 Asociación de Bancos de México, "Comunicado de prensa", El Economista, 2 de julio de 2018.

117 "Consejo Agropecuario llama a trabajar en unidad con próximo gobierno”, El Informador, 2 de julio de 2018. 
- Propone diálogo respetuoso y de colaboración: CCE

- Ante la división en la contienda, propone la unión de todos: CCE, Coparmex

- Seremos aliados del presidente en la lucha contra la corrupción: Coparmex

- Si se mantienen certidumbre y estabilidad, habrá crecimiento: Coparmex

- Comienza una nueva era en la vida democrática: Coparmex

- Defenderemos la libertad de expresión: Coparmex

- Se propone crear una fiscalía general autónoma: Coparmex

- Exige respeto del presidente a los empresarios: Coparmex

- Apoyará y trabajará con las autoridades electas: Concanaco Servytur

- La numerosa participación de la ciudadanía fortalece la democracia mexicana: Concanaco Servytur

- No hay sospechas de fraude que pudieran deslegitimar a las autoridades democráticamente electas: Concanaco Servytur

- Propone a sus organizaciones agremiadas hacer propuestas para integrarlas al Plan Nacional de Desarrollo del nuevo gobierno federal: Concanaco Servytur

- Felicita a López Obrador por el triunfo en los comicios y le expresa el compromiso de trabajar junto con su gobierno: Concamin

- Desea que los nuevos equilibrios políticos produzcan mejores gobiernos, que respondan con eficacia a la demanda social de mayor seguridad, supresión de la corrupción, pleno Estado de derecho y progreso económico y social sin distinción de grupos o regiones: Concamin 
- La agenda requiere del trabajo coordinado de los empresarios, la comunidad académica y científica, la sociedad y el gobierno; por lo tanto, procurará los acercamientos necesarios para iniciar un diálogo constructivo: Concamin

- Reconoce el triunfo de López Obrador y declara que trabajará en conjunto con los tres órdenes de gobierno, en especial con el presidente, para impulsar estrategias y políticas públicas que promuevan la economía del país y así, llevar los beneficios del seguro a más mexicanos, y contribuir al bienestar de las familias: AMIS

- Refrenda su compromiso de trabajar con quien los ciudadanos han decidido sea al próximo presidente de la República para el periodo 2018-2024: AMIS

- Felicita a López Obrador: CNA

- Le ofrece trabajar en la construcción de un campo ganador: CNA

- Alienta al sector agropecuario a superar las diferencias políticas y a trabajar en unidad con el gobierno: CNA

Dos días después de la elección presidencial del 1 de julio de 2018, la revista empresarial Forbes declaró: "Se inclina el Consejo Mexicano de Negocios y colma de felicitaciones a AMLo por su triunfo. Tras haber manifestado su desacuerdo con Andrés Manuel López Obrador, e incluso haber intimidado a sus trabajadores para que no votasen por el mismo, el Consejo Mexicano de Negocios reculó y ha colmado de felicitaciones al tabasqueño...”.

El primer encuentro de los empresarios con López Obrador después de las elecciones tuvo lugar a puerta cerrada el 4 de julio en el hotel Camino Real, donde acudieron los representantes del CCE y las principales organizaciones que lo constituyen. Entre los temas que los empresarios deseaban 
poner sobre la mesa estaba el futuro del nuevo aeropuerto internacional de la Ciudad de México, uno de los asuntos que ha causado más desencuentros entre el actual presidente y la cúpula empresarial. ${ }^{118}$

Al término de la reunión, López Obrador dijo que "fue una reunión caracterizada por la confianza y nosotros vamos a saber corresponder a la confianza que han depositado en nosotros millones de mexicanos, y en este caso los empresarios de México". Aseguró que hubo mucha confianza tanto en México como en el ámbito internacional, al señalar que así lo han expresado primeros ministros, presidentes y jefes de Estado. "Vamos a la transformación de México por el camino de la concordia -enfatizó-. No se va a imponer nada. Vamos a argumentar, vamos a convencer". Advirtió que aun cuando su partido tiene mayoría en la Cámara de Diputados y en la Cámara de Senadores, "no se va a actuar de manera prepotente. No se va a imponer nada”. Parafraseando a Benito Juárez, dijo: "Nada por la fuerza, todo por la razón y el derecho”. Afirmó que actuará con mucha responsabilidad. "Estamos construyendo una auténtica democracia -recalcóno una dictadura". Aclaró que "va a haber austeridad en el gobierno; se tienen que liberar estos fondos que van a salir del ahorro que se va a hacer con las medidas que vamos a tomar, para que no se tengan que financiar éste y los otros programas". Dijo que el desarrollo no se va a financiar "ni con aumentos de impuestos ni con aumentos de deuda pública; es decir, no va a haber déficit. Y tampoco va a haber gasolinazos. "Yo estoy seguro -finalizó- que nos va a alcanzar el presupuesto".

Por su parte, los empresarios salieron muy optimistas de la reunión y en unas cuantas frases sintetizaron su percepción: Pablo Castañón dijo: "Necesitamos un gobierno sólido

118 Gonzalo García Crespo, "Los empresarios y López Obrador se reúnen en busca de un diálogo", Expansión, 4 de julio de 2019, https:/ / politica.expansion.mx/presidencia/2018/07/04/los-empresarios-y-lopez -obrador-se-reunen-en-busca-de-un-dialogo-franco (consulta del 15 de junio de 2019). 
y fuerte que fortalezca la unidad de los mexicanos y la confianza. El ambiente de la reunión fue de confianza y certidumbre". Claudio X. González complementó: "Para hacer lo que tenemos que hacer, para hacer de México un país más incluyente, más próspero y que realmente le saquemos todo su potencial". Alejandro Ramírez dijo: "[estamos] muy optimistas de lo que podemos hacer en colaboración conjunta el sector privado con el nuevo gobierno". Carlos Rojo (director general de Interacciones) expresó: "Y esto que se está planteando, es la posibilidad de lograr eso; de generar más empleo y de que los jóvenes puedan incorporarse a las empresas con la facilidad de estar trabajando y estudiando al mismo tiempo, y que el gobierno apoyaría a las empresas”. Bosco de la Vega concluyó: "Ya habíamos hecho el trabajo con todos los candidatos y hoy lo que vi fue una excelente reunión público-privada donde el interés es México". ${ }^{119}$

Además, algunos grupos empresariales, como el Grupo Lala, de Eduardo Tricio -otro de los empresarios que había tenido fuertes choques con López Obrador- llamaron en lo individual a los mexicanos a contribuir cívicamente para que México avance por el camino de la paz y la prosperidad. "Es tiempo de renovar-dijo- nuestro empeño de crecer y cuidar a México. Trabajemos unidos por nuestra patria, y junto al presidente electo y su equipo contribuyamos al país que soñamos". ${ }^{120}$

La postura de las grandes empresas transnacionales ha sido también de acercamiento. Claudia Jañez, nueva presidenta del CEEG, en su mensaje al asumir su cargo, declaró a nombre de las 51 empresas asociadas, que el documento de esta organización titulado La visión México 2030 coincide en varios puntos con las propuestas del gobierno de López Obrador. Añadió que concuerdan "plenamente en la necesidad de

119 "Las 10 frases del encuetro entre AMLo y los empresarios", Expansión, 4 de julio de 2018.

120 "Eduardo Tricio de Lala llama a trabajar juntos por la prosperidad": "A través de una carta, el presidente de Grupo Lala dijo que es tiempo de contribuir para que México avance por el camino de la paz y la prosperidad", Forbes México, 3 de julio de 2018. 
trabajar por un México más próspero y equitativo. Todos queremos que el país crezca más aceleradamente y con mayor inclusión social [...] les manifiesto mi total disposición para establecer un diálogo constructivo y permanente entre el gobierno y el CEEG, para identificar sinergias y trabajar de cerca, para avanzar hacia la transformación que todos anhelamos". 121

\section{Conclusiones}

Las relaciones de los empresarios con el gobierno de Enrique Peña Nieto fueron tan heterogéneas como los propios empresarios. En términos generales, el balance que hacen las organizaciones de la iniciativa privada sobre su gobierno es positivo y quedaron más satisfechos que con las administraciones panistas, ya que vieron materializarse las esperadas reformas estructurales. Entre los pequeños empresarios los principales reclamos al gobierno de Peña Nieto son que no cumplió sus promesas de campaña y que tuvieron muchos problemas por la inseguridad, la falta de créditos y el sesgo en los apoyos hacia las medianas empresas, así como la falta de difusión de esos apoyos, y la dificultad para conseguirlos por los requisitos, los trámites y las reglas de operación. También le hicieron reclamos en torno a la corrupción y la burocracia.

Para los empresarios que representan sus intereses en el CCE, el gobierno de Peña Nieto dejó activos importantes que preservar, entre ellos, las reformas estructurales y la estabilidad macroeconómica, incluida la baja inflación, lo que permitió un crecimiento, aunque fuera moderado. También percibieron que hubo mejoría en el clima de negocios debido a la disminución de trámites y a reglas más claras. Apreciaron el apoyo de ese gobierno al libre comercio al renovar y modernizar los acuerdos comerciales.

121 "Mensaje de Claudia Jañez", art. cit. 
Las principales limitaciones que observan son el bajo crecimiento de la economía, la escasez de inversiones en infraestructura, las diferencias y desequilibrios regionales, y la falta de oportunidades de empleo. Especialmente, destacaron como limitaciones los niveles de inseguridad y violencia, la debilidad del Estado de derecho, los problemas de corrupción y de impunidad, lo que conduce a una crisis de confianza en la autoridad y en las instituciones.

Para el CCE y para gran parte de las organizaciones que representan los intereses de las empresas medianas y grandes, la contienda electoral de 2018 significó un desafío. A diferencia de 2006, sus organizaciones no tuvieron injerencia en el proceso electoral, aunque algunos de los grandes empresarios buscaron inducir el voto de sus empleados y, por extensión, el de la sociedad; así lo manifestaron sus cartas y desplegados periodísticos. Sin embargo, los resultados electorales le dieron el triunfo con gran margen al candidato que rechazaban y, en ese sentido, perdieron. Ante ese hecho, todas las organizaciones reconocieron el triunfo. Muchas de ellas incluso cumplimentaron a Andrés Manuel López Obrador, mientras que otras se limitaron congratularse por la paz y tranquilidad durante las elecciones y felicitaron a los mexicanos en general. Después de la elección, se dieron varios acercamientos con diversos hombres de negocios y organizaciones, los cuales continuaron ya con López Obrador como presidente en funciones, incluso con algunos de los empresarios con los que había tenido los mayores enfrentamientos. En algunos casos ha habido un entendimiento y una promesa abierta de cooperación, como con el programa social Jóvenes Construyendo el Futuro, mediante el cual las empresas recibirán durante un año a jóvenes que serán becados por el gobierno y que podrían después ser contratados (sin compromiso) por ellas. El 13 de junio de 2019 tuvo lugar la firma de un acuerdo entre Alfonso Romo, titular del Consejo para el Fomento a la Inversión, el Empleo y el Crecimiento Económico y el CCE, del que los empresarios se sintieron satisfechos por la promesa del presidente de eliminar obstáculos a la in- 
versión y de generar certeza. Carlos Salazar Lomelín, presidente del CCE desde enero de 2019, dijo: "Nos llena de satisfacción el compromiso que escucharon del presidente de la república. Él, personalmente, estará desatorando proyectos, ayudando a que se viabilicen, tratando de fortalecer el Estado de derecho que se requiere para lo mismo". Y añadió: "Lo que presentamos al presidente y acordamos, es hacer que la inversión total vaya hasta el $25 \%$ del PIB, esto significa [...] que vamos a trabajar no de un día para otro, evidentemente, sino en los próximos dos años aumentar [...] 35000 millones de dólares la inversión que se hace en México”. Destacó el actual presidente del CCE que las empresas representadas por ese organismo identifican unos mil proyectos en los que se puede invertir en sectores como el energético, de infraestructura, y proyectos sociales y regionales. ${ }^{122}$

Esos encuentros no significan que en esta relación todo sea miel sobre hojuelas, ni que los empresarios estén contentos con muchas decisiones del nuevo gobierno, especialmente con la cancelación del nuevo aeropuerto de la Ciudad de México. Sin embargo, hay demasiados compromisos e intereses de la iniciativa privada en México y no les interesa un distanciamiento con el gobierno. Tampoco interesa al presidente tenerlos como enemigos. El gobierno de López Obrador ha echado para atrás la reforma educativa, pero no ha revertido la reforma energética, la más importante para ellos y para el capital transnacional que ganó las primeras licitaciones. Tampoco tiene previsto emprender una reforma fiscal, al menos en los primeros tres años de gobierno. Ha promovido una reforma laboral que facilite la democratización de los sindicatos. Además, les ha convocado y prometido seguridad para invertir en México.

122 Cristóbal Martínez Riojas, “AMLo y los empresarios viven una segunda luna de miel”, Expansión, 14 de junio de 2019, https:/ / expansion. $\mathrm{mx} /$ economia/2019/06/14/amlo-y-los-empresarios-viven-una-segundaluna-de-miel (consulta del 1 de julio de 2019). 
Por otro lado, entre las críticas que desde diversos sectores de la sociedad se hacen al desempeño del primer año de gobierno de López Obrador, están la cancelación del nuevo aeropuerto internacional de la Ciudad de México; los megaproyectos que se han aprobado sin estudios previos y sin licitación para la construcción de la refinería de Dos Bocas (cuya licitación se declaró desierta), el Tren Maya y el aeropuerto de Santa Lucía, ante los cuales sus opositores han interpuesto amparos. También, las adjudicaciones directas y de manera centralizada de contratos; la entrega directa de recursos a la población, en lugar de hacerlos pasar por instituciones y organizaciones de la sociedad civil, lo que se ha sido interpretado por sus opositores como una política clientelista con intenciones electorales. Renglón aparte es la falta de aplicación de su política anticorrupción, que no ha llevado a la justicia a ningún alto funcionario de la pasada administración que tanto se había criticado, o de la actual, lo que algunos consideran como un "pacto de impunidad", así como el debilitamiento de las instituciones autónomas (INE e IFAI) a través de la reducción de su financiamiento; la ineficacia de su política para contener la violencia; la creación de la Guardia Nacional y su empleo para contener las olas de migrantes centroamericanos que intentan transitar por México para llegar a Estados Unidos, bajo la amenaza hecha por Trump de aumentar aranceles a productos mexicanos.

En cuanto a los indicadores, las calificadoras crediticias y los expertos en riesgos de inversión están presionando a México y cuestionando su orientación económica, y han reducido la confianza en el país. De acuerdo con un reporte de $E l$ Economista, "los bonos de deuda de Pemex han sido degradados por Fitch Ratings a niveles especulativos, pero no se han pronunciado Standard \& Poor's y Moody's, las otras dos calificadoras de mayor operación mundial". ${ }^{123}$ Por otra parte, la

123 Yolanda Morales, "Plan de negocios de Pemex será clave", El Economista, 10 de junio de 2019, https://www.eleconomista.com.mx/merca- 
violencia no da signos de cambio, ya que los asaltos, los secuestros y los homicidios no ceden y 2019 se convirtió en el año más violento de la historia moderna de México.

Sin embargo, en lo que toca a los megaproyectos, se han realizado reuniones del presidente con los empresarios, a quienes al parecer los ha invitado a invertir y ellos habrían aceptado. Por otra parte, el tipo de cambio y la inflación se han mantenido estables por el manejo de las finanzas públicas y el respeto a la autonomía de Banco de México. Además, el T-MEC fue ratificado por el Congreso mexicano. Una nota de The New York Times, en su edición en español sintetiza algunos de los logros: a un año del triunfo electoral, López Obrador "ha tenido pocos éxitos tangibles, pero dos éxitos reales: cuestionar las prioridades públicas fijadas por las elites mexicanas y aprobar una reforma laboral histórica". ${ }^{124}$

\section{REFERENCIAS BIBLIOGRÁFICAS}

"Acuerdo Nacional para la Unidad, el Estado de Derecho, el Desarrollo, la Inversión y el Empleo", Acuerdo de Chapultepec, México, 29 de septiembre de 2005, https://www.acuerdodechapultepec.org

"Acusa Ernesto Cordero a Ricardo Anaya, en la PGR, de lavado de dinero", Aristegui Noticias, 11 de junio de 2018, https://aristeguinoticias.com/1106/mexico/acusa-ernesto-cordero-a-ricardo-anaya-en-la-pgr-de-lavado-de-dinero/

"Agresiones en contra del sector empresarial y sus organizaciones", Consejo Coordinador Empresarial, 20 de enero de 2015, https:/ / www.cce.org.mx/a-los-representantes-de-los-tres-po deres-de-la-union-en-los-tres-ordenes-de-gobierno-2/

dos/Plan-de-Negocios-de-Pemex-sera-clave-20190610-0072.html (consulta del 30 de junio de 2019).

124 Viridiana Ríos, "Los verdaderos éxitos de AMLo", The New York Times, 17 de junio de 2019, https://www.nytimes.com/es/2019/06/17/lopez-obrador-economia/ (consulta del 30 de junio de 2018). 
Alba Vega, Carlos y Mauricio Rodríguez, "Trabajo y desigualdad. La precarización del trabajo y de los salarios de 2000 a 2017”, en Melina Altamirano y Laura Flamand (coords.), Desigualdades en México 2018, México, El Colegio de México (en prensa). Alba Vega, Carlos, "Los empresarios y la democracia en México", Foro Internacional, 96-1 (2006), pp. 122-149.

Alba Vega, Carlos, "Policy analysis and public policy in the private sector", en José Luis Méndez y Mauricio I. Dussauge-Laguna (eds.), Policy Analysis in Mexico, International Library of Policy Analysis 9, Bristol, Reino Unido / Chicago, EE.uU., Bristol University Press, 2017, pp. 223-238.

"Alerta Herdez por futuro difícil", NNC.mx, 27 de mayo de 2018, https://www.nnc.mx/articulo/nacional/alerta-herdez-por-futuro-dificil/1527434670.

“AMLO: 'Algunos de los que avalan el desplegado 'Así no' (CMN) han impedido la democracia del país'”, Sin Embargo, 3 de mayo de mayo 2018, https://www.sinembargo.mx/03-05-2018/341 4571

Arriola, Carlos, "La Concamin", en Carlos Alba Vega (coord.), Historia y desarrollo industrial de México, México, Concamin, 1988, pp. 233-275.

Arriola, Carlos, "La Ley de Cámaras Empresariales y sus Confederaciones", Foro Internacional, 37 (1997), pp. 634-660.

Arturo Solís, "La reforma energética tuvo impacto negativo: empresarios", Forbes, 18 de abril de 2018.

Asociación de Bancos de México, "Comunicado de prensa", ElEconomista, 2 de julio de 2018.

AzIz Nassif, Alberto, Chihuahua: historia de una alternativa, La Jornada / CIESAS, 1994

Basave Kunhardt, Jorge y María Teresa Gutiérrez-Haces, "Localización geográfica y sectores de inversión: factores decisivos en el desempeño de las multinacionales mexicanas durante la crisis", Journal of Economics, Finance and Administrative Science (2013), núm. 34, pp. 34-44.

Bizberg, Ilán, "Auge y decadencia del corporativismo", en Ilán Bizberg y Lorenzo Meyer (coords.), Una historia contemporánea de México: transformaciones y permanencias, México, Océano, 2003, pp. 313-366. 
Briz Garizurieta, Marcela, "El Consejo Mexicano de Hombres de Negocios en la transición hacia un nuevo modelo de desarrollo, tesis de doctorado en Ciencias Políticas y Sociales, unam, 2006.

Briz Garizurieta, Marcela, El Consejo Mexicano de Hombres de Negocios, surgimiento y consolidación, México, UNAM, 2002.

Buendía Laredo, Jorge, "Autoritarismo y participación empresarial: La Confederación Patronal de la República Mexicana, 1970-1988", tesis de licenciatura en Relaciones Internacionales, Centro de Estudios Internacionales, El Colegio de México, 1989.

CAMP, Roderic Ai, Entrepreneurs and politics in twentieth century Mexico, New York/ Oxford, Oxford University Press, 1989.

Carton de Grammont, Hubert, Los empresarios agrícolas y el Estado. Sinaloa, 1893-1984, México, IIS-UnAM, 1990.

Castro Espinosa, Álvaro, "Tan lejos de Europa y tan cerca de los Estados Unidos: orígenes, negociación y perspectivas del acuerdo político y comercial entre México y la Unión Europea”, Foro Internacional, 43 (2003), pp. 893-916.

Cerutti, Mario, Burguesía y capitalismo en Monterrey, 1850-1910, Monterrey, Claves Latinoamericanas, 1983

Cerutti, Mario, Propietarios, empresarios y empresa en el norte de México: Monterrey: de 1848 a la globalización, México, Siglo xxi, 2000.

"Cierran investigación sobre financiación de Odebrecht a campaña de Peña Nieto", EFE, 20 de junio de 2019, https:/ /www.efe.com/ efe/america/mexico/cierran-investigacion-sobre-financiacion-de-odebrecht-a-campana-pena-nieto/50000545-4005600 (consulta del 6 de diciembre de 2019).

"Con Peña Nieto cerraron 350 mil empresas chicas; se dedicó a las grandes, acusan", Vanguardia.mx, 2 de septiembre de 2018, https://vanguardia.com.mx/articulo/con-pena-nieto-cerraron-350-mil-empresas-chicas-se-dedico-las-grandes-acusan (consulta del 21 de febrero de 2020).

Concheiro, Elvira, El gran acuerdo. Gobierno y empresarios en la modernización salinista, México, Instituto de Investigaciones Económicas, UNAM / Era, 1996. 
"Consejo Agropecuario llama a trabajar en unidad con próximo gobierno", El Informador, 2 de julio de 2018.

Consejo Coordinador Empresarial, CCE, "Un balance de cara a la transmisión de poderes en el ejecutivo" (comunicado), México, CCE, 25 de noviembre de 2018, https://www.cce.org. $\mathrm{mx} /$ un-balance-de-cara-a-la-transmision-de-poderes-en-el-eje cutivo/

Consejo Ejecutivo de Empresas Globales, CEEG, "El CEEG en cifras", http:/ / ceeg.mx/ (consulta del 28 de junio de 2019).

Consejo Ejecutivo de Empresas Globales, CEEg, México 2030 ante la cuarta revolución industrial. Propuestas para la productividad, el crecimiento y la inclusión social, México, 2016, http://ceeg.mx/vision-mexico-2030-ante-la-cuarta-revolucion-industrial/

"Constructora Marusa, sA de CV (Constructora Marusa)", BNamericas, https://www.bnamericas.com/es/perfil-empresa/constructora-marusa-sa-de-cv-constructora-marusa

Cruz Serrano, Noé, "Pemex favorece a 21 firmas proveedoras en el sexenio", El Universal, 2 de mayo de 2018, https://www.eluniversal.com.mx/cartera/pemex-favorece-21-firmas-proveedoras-en-el-sexenio

Cruz Vargas, Juan Carlos, "Sin mencionar a amlo, el cce dice que entablará colaboración con las autoridades electas", Proceso, 1 de julio de 2018.

Cuevas, Stephanie, "Baillères felicita a López Obrador por carta a Trump sobre aranceles”, El Financiero, 3 de junio de 2019.

"Eduardo Tricio de Lala llama a trabajar juntos por la prosperidad". Forbes México, 3 de julio de 2018.

“Él es el petrolero 'no. 1 de México'... después de Pemex”, SIPSE.COM, https://sipse.com/mexico/reforma-energetica-grupo-diavazprepara-inversion-apertura-pemex-144951.html

Elizondo, Carlos, "In Search of Revenue: Tax Reform in Mexico under the Administrations of Echeverría and Salinas", documento mimeografiado, México, Oxford, CIDE , Nuffield College, 1992.

Elizondo, Carlos, "The making of a new alliance: the privatization of the banks in Mexico", documento de trabajo, Estudios Polí- 
ticos, México, Centro de Investigación y Docencia Económicas, 1993.

"Empresarios niegan presión para que se unan Meade y Anaya", El Financiero, 2 de mayo de 2019, https://www.elfinanciero.com. $\mathrm{mx}$ /elecciones-2018/los-empresarios-no-tenemos-candidatoni-partido-cce (consulta del 14 de junio de 2018).

Gobierno de México y la Comisión Nacional de Hidrocarburos ( $\mathrm{CNH})$, Bóveda digital de contratos de la $\mathrm{CNH}$, https:/ / www.gob. $\mathrm{mx} / \mathrm{cnh} /$ articulos/boveda-digital (consulta del 21 de febrero de 2020)

Gobierno de México, Comisión Nacional de Hidrocarburos, CNH, Reservas de hidrocarburos en México, conceptos fundamentales y análisis, 2018, México, Gobierno de México, CNH, 2019, https:// www.gob.mx/cms/uploads/attachment/file/435679/201902 07._CNH-_Reservas-2018._vf._V7.pdf

Ernst \& Young México, Nueva era de la energía en México, Ministerio Federal de Economía y Energía de la República Federal de Alemania /Secretaría de Energía de México, México, 2018, https://www.energypartnership.mx/fileadmin/user_upload/ mexico/media_elements/reports/NuevaEraEnergiaMexico_ ESP.pdf

García, Ariadna, "Empresarios cierran filas con Meade Kuribreña”, El Universal, 26 de junio de 2018.

García Crespo, Gonzalo, "Los empresarios y López Obrador se reúnen en busca de un diálogo", Expansión, 4 de julio de 2019, https://politica.expansion.mx/presidencia/2018/07/04/losempresarios-y-lopez-obrador-se-reunen-en-busca-de-un-dialo go-franco (consulta del 15 de junio de 2019).

GonzÁlez, Lilia, "Cúpulas de la IP condenan expresiones de AMLO”, El Economista, 3 de mayo de 2018, https:/ / www.eleco nomista.com.mx/politica/Cupulas-de-la-IP-condenan-expre siones-de-AMLO-20180504-0021.html

GonzÁlez, Luis Miguel, "Petroleras privadas mexicanas: ¿quién es quién?”, El Economista, 13 de julio de 2017, https://www.eleco nomista.com.mx/opinion/Petroleras-PRIvadas-mexicanasquien-es-quien-20170714-0001.html 
Guadarrama Olivera, Rocío, Los empresarios norteños en la sociedad y la política del México moderno. Sonora /1929-1988, México, El Colegio de México / El Colegio de Sonora / uAm, 2001.

Hernández, Angélica, "Empresarios presentan 10 mil amparos ante reforma fiscal", El Financiero, 5 de marzo de 2014.

Hernández, Leticia, “¿A quién beneficia que sean deducibles al $100 \%$ las prestaciones laborales?”, El Financiero, 18 de diciembre de 2018.

Hernández, Marcela, "Reestructuración del empresariado y de las grandes corporaciones", en Enrique de la Garza (ed.), La situación del trabajo en México: el trabajo en la crisis, México, UAM / Plaza y Valdés, 2012, pp. 697-730.

Horneffer Rodríguez, Francisco, "El Estado y la inversión extranjera directa de las empresas mexicanas", tesis de licenciatura en Relaciones Internacionales, El Colegio de México, Centro de Estudios Internacionales, 2012.

"Inversiones en el sector energético en México superarán los 100,000 mdd en 2018", Economiahoy.mx, 9 de enero de 2018, https:/ /www.economiahoy.mx/economia-eAm-mexico/noti cias/8856227/01/18/Inversiones-en-el-sector-energetico-enMexico-superaran-los-100000-mdd-en-2018.html

Jañez, Claudia, “Mensaje de Claudia Jañez”, México, CEEg, http:/ / ceeg.mx (consulta del 28 de junio de 2019).

"La casa blanca de Enrique Peña Nieto (investigación especial)", Aristegui Noticias, 9 de noviembre de 2014, https://aristeguinoticias.com/0911/mexico/la-casa-blanca-de-enrique-pena nieto/

"La familia política de Javier Jiménez Espriú, colaborador de AMLO, es socia de filial de Odebrecht", Vanguardia.mx, 13 de junio de 2018, https://vanguardia.com.mx/articulo/la-familia-poli tica-de-javier-jimenez-espriu-colaborador-de-amlo-es-socia-defilial-de

"La reforma energética, la participación privada y el descubrimiento gigante", México, Unidad de Análisis Estratégico, Connection MéxicoGlobal,2017, http:/ / www.connectionmexicoglobal. com/wp-content/uploads/2017/08/RE-Sierra-Oil-P.pdf 
"Las 10 frases del encuentro entre AMLO y los empresarios", Expansión, 4 de julio de 2018.

Labastida, Julio (comp.), Grupos económicos y organizaciones empresariales en México, México, Alianza Editorial Mexicana-unAM, 1986.

LARA, Juan Antonio, "Decepciona a empresarios de NL reforma fiscal", El Financiero, 10 de septiembre de 2013.

"Las diez principales frases de Eloy Vallina", Tiempo la noticia digital, 25 de mayo de 2018, http://www.tiempo.com.mx/noti cia/131815-las_10_principales_frases_eloy_s_vallina_laguera_ eloy_vallina_comunicado_regresion_y_mesianismo_autori tario/ 1

"Lista completa de los miembros de la Comisión Trilateral (febrero de 2003)", Solidaridad.net, 28 de marzo de 2003, https:// solidaridad.net/lista-completa-de-los-miembros-de-la-comision-trilateral-febrero-de-2003-248/ (consulta del 30 de junio de 2019).

"Llama AMLo a adversarios y mafia del poder que se preparen, porque ya es tiempo que haya democracia en México", boletín de campaña-042, 1 de mayo de 2018.

"Los 300 empresarios", Lideres Mexicanos, https://lideresmexicanos.com/300/jose-ramiro-garza-cantu-los-300/

"Lozano: Empresarios presionan para que Meade y Margarita declinen por Anaya", Nación 321, 1 de mayo de 2019, https://www. nacion321.com/elecciones/lozano-empresarios-estan-presio nando-para-que-meade-y-margarita-declinen (consulta del 14 de junio de 2019).

LunA, Matilde, "Las asociaciones empresariales y el Estado panista”, en Enrique de la Garza Toledo (coord.), La situación del trabajo en México, 2012. El trabajo en la crisis, México, Plaza y Valdés Editores, 2012.

LunA, Matilde, "Los empresarios en el proceso de cambio político", Metapolítica (2007), núm. 54, pp. 72-78.

Luna, Matilde y Ricardo Tirado, El Consejo Coordinador Empresarial. Una radiografía, Proyecto Organizaciones Empresariales en México, Cuaderno de Investigación 1, México, IIs / FCPys, UNAM, 1992. 
"Magnates 'arropan' a Meade y piden a sociedad razonar su voto", Proceso, 25 de junio de 2018.

Maldonado, Mario, "Cuando los empresarios cambiaron a Meade por Anaya”, El Universal, 20 de junio de 2018, https://www. eluniversal.com.mx/columna/mario-maldonado/cartera/ cuando-los-empresarios-cambiaron-meade-por-anaya (consulta del 14 de junio de 2019).

Maldonado, Mario, "Empresarios van con Anaya si Meade no levanta", El Universal, 23 de abril de 2018.

Maldonado, Mario, "Los mensajes de AmLo a los petroleros", $E l$ Universal, 12 de septiembre de 2018, https://www.eluniversal. com.mx/columna/mario-maldonado/cartera/los-mensajesde-amlo-los-petroleros

Martín Cullell, Jon y Lucía Bohórquez, "México ordena el arresto del exdirector de Pemex y logra la captura de un empresario por el 'caso Odebrecht' ", El País, 29 de mayo de 2019, https://elpais.com/internacional/2019/05/28/mexico/15 59055206_285704.html (consulta del 3 de diciembre de 2019).

Martínez, Diego, "Consejo Mexicano de Negocios ofrece colaboración con AMLO para generar más empleos”, Aristegui Noticias, 1 de julio de 2009, https://aristeguinoticias.com/0107/mexi co/consejo-mexicano-de-negocios-ofrece-colaboracion-con amlo-para-generar-mas-empleos/ (consulta del 14 de junio de 2019).

Martínez Riojas, Cristóbal, "Amlo y los empresarios viven una segunda luna de miel”, Expansión, 14 de junio de 2019, https:/ / expansion.mx/economia/2019/06/14/amlo-y-los-empresa rios-viven-una-segunda-luna-de-miel (consulta del 1 de julio de 2019).

Méndez, Rocío, "Meade tiene una visión clara sobre el México del futuro: CCE", MVS Noticias, 28 de noviembre de 2017, https:// mvsnoticias.com/noticias/economia/meade-tiene-una-visionclara-sobre-el-mexico-del-futuro-cce-311/

MÉndez, Rocío, "Redoblarán empresarios esfuerzos e inversiones en el sector energético", Mvs Noticias, 16 de enero de 2019, https://mvsnoticias.com/noticias/nacionales/redoblaran- 
empresarios-esfuerzos-e-inversiones-en-el-sector-energetico/ (consulta del 15 de junio de 2019).

Mendoza Escamilla, Viridiana, "Concanaco trabajará con autoridades que los mexicanos eligieron democráticamente”, Forbes, 1 de julio de 2019.

Mexicanos Contra la Corrupción y la Impunidad, “¿Quién es Sergio Moro?”, YouTube, 31 de julio de 2017, https://www.youtu be.com/watch?v=11_K1 tezcIg

"Micro, pequeñas y medianas empresas, olvidadas en el gobierno de EPN", Polemón, 11 de septiembre de 2018, https:/ / polemon. $\mathrm{mx} /$ micro-pequenas-y-medianas-empresas-olvidadas-en-go bierno-de-epn (consulta del 9 de junio de 2019).

Mizrahi, Yemile, "La nueva oposición conservadora en México: la radicalización política de los empresarios norteños", Foro Internacional, 32 (1992), pp. 744-771.

Morales, Yolanda, "Plan de negocios de Pemex será clave", El Economista, 10 de junio de 2019, https://www.eleconomista.com. $\mathrm{mx} /$ mercados/Plan-de-Negocios-de-Pemex-sera-clave-20 190610-0072.html (consulta del 30 de junio de 2019).

Muñoz Cota Callejas, José, "El Consejo Coordinador Empresarial en el sexenio de Vicente Fox", tesis de maestría en Ciencia Política, El Colegio de México, 20 de agosto de 2009.

"Nadie negocia conmigo. Candidatos y sus campañas corren en otro camino: EPN", Expansión Política, 2 de mayo de 2018, https:// politica.expansion.mx/presidencia/2018/05/02/nadie-nego cia-conmigo-candidatos-y-sus-campanas-corren-en-otro-caminoepn (consulta del 14 de junio de 2019).

Navarro, Andrea, "Líderes empresariales parecen respaldar a Meade”, El Financiero, 29 de noviembre de 2017, https://www. elfinanciero.com.mx/nacional/lideres-empresariales-pare cen-respaldar-a-meade (consulta del 13 de junio de 2019).

"No más corruptos impunes: empresarios de la Coparmex se manifiestan en el Ángel”, Animal Político, 16 de junio de 2016, https://www.animalpolitico.com/2016/06/no-mas-corruptosimpunes-empresarios-se-manifiestan-en-el-angel-por-leyes-an ticorrupcion/ 
Ortega, Octavio, “¿Quiénes son los empresarios que piden no votar por AMLo?”, La Nación, 31 de mayo de 2018.

Ortiz Rivera, Alicia, "Consejo Mexicano de Hombres de Negocios: ¿Poder tras la silla presidencial?”, tesis de maestría en Sociología Política, México, Instituto Dr. José María Luis Mora, 1998.

Pantoja, Sara, "En sexenio de Peña, el Conacyt transfirió el 48\% de sus recursos a la IP: Álvarez-Buylla”, Proceso, 27 de junio de 2019.

"Peña Nieto deja México estable económicamente: empresarios", Forbes, 25 de noviembre de 2018, https:/ /www.forbes.com.mx/ empresarios-destacan-que-pena-nieto-deja-mexico-estable-eneconomia/ (consulta del 9 de junio de 2019).

Ponce, Karla, "Estas fueron las 11 reformas que marcaron el gobierno de Peña Nieto", Excélsior, 26 de noviembre de 2018, https://www.dineroenimagen.com/economia/estas-fueronlas-11-reformas-que-marcaron-el-gobierno-de-pena-nieto/ 104937 (consulta del 29 de junio de 2019).

Pozas, María de los Ángeles, Estrategia internacional de la gran empresa mexicana en la década de los noventa, México, El Colegio de México, Centro de Estudios Sociológicos, 2002.

Puga, Cristina, Los empresarios organizados y el Tratado de Libre Comercio de América del Norte, México, Facultad de Ciencias Políticas, UNAM / Miguel Ángel Porrúa, 2004.

Quintana, Enrique, "Una reforma impopular pero efectiva", $E l$ Financiero, 23 de noviembre de 2017.

Ramírez TAMAYo, Zacarías, "Grupo IDESA, tras un mercado energético de 2500 mdd”, Forbes, 20 de octubre de 2016, https:// www.forbes.com.mx/grupo-idesa-tras-un-mercado-energeticode-2500-mdd/

Ramos, Dulce, “¿Quiénes llevarán los intereses de las televisoras al Congreso?”, Animal Político, 4 de noviembre de 2012, https:// www.animalpolitico.com/2012/09/telebancadas-quienes-lleva ran-los-intereses-de-las-televisoras-al-congreso/ (consulta del 4 de diciembre de 2019).

Rangel M., J. Jesús, "Prácticas ilegales por contratos de Pemex", Milenio, 29 de diciembre de 2016, https://www.milenio.com/ 
opinion/jesus-rangel/estira-afloja/practicas-ilegales-por-con tratos-de-pemex

"Respalda Coparmex a AMLo", Excélsior, 2 de julio de 2018.

Ríos, Viridiana, "Los verdaderos éxitos de AmLo", The New York Times, 17 de junio de 2019, https://www.nytimes.com/es/2019/ 06/17/lopez-obrador-economia/ (consulta del 30 de junio de 2018).

Robles de la Rosa, Leticia, "PRD resquebraja Pacto por México; busca detener la reforma energética”, Excélsior, 29 de noviembre de 2019.

RoDRíGUez, Israel, “AMIS expresa felicitación a AMLO”, La Jornada, 2 de julio de 2018, https:/ /www.jornada.com.mx/ultimas/2018/ 07/02/amis-expresa-felicitacion-a-amlo-341.html (consulta del 15 de junio de 2019).

Rosa, Eduardo de la, "Sector industrial felicita a AMLO por ganar comicios", Milenio, 1 de julio de 2018, https://www.milenio. $\mathrm{com} /$ negocios/sector-industrial-felicita-amlo-ganar-comicios (consulta del 15 de junio de 2019).

Servicios de Extracción Petrolera Lifting de México, sA de cv (Servicios de Extracción Petrolera Lifting de México), BNamericas, https://www.bnamericas.com/es/perfil-empresa/serviciosde-extraccion-petrolera-lifting-de-mexico-sa-de-cv-servicios-deextraccion-petrolera-lifting-de-mexico

Sesión con el Dr. José Antonio Meade, candidato de la Coalición Todos por México, Ciudad de México, 7 de mayo de 2018.

Sesión con el Lic. Andrés Manuel López Obrador, candidato de la Coalición Juntos Haremos Historia, Ciudad de México, 24 de abril de 2018.

Shadlen, Kenneth C., Democratization Without Representation: The Politics of Small Industry in Mexico, University Park, Pennsylvania, Penn State Press, 2010.

"Si a EPN lo marcó la casa blanca, Texcoco marcará el sexenio de AMLO: Coparmex", 30 de octubre de 2018, http://diariotiempo.mx/economia/si-a-epn-lo-marco-la-casa-blanca-texcocomarcara-el-sexenio-de-amlo-coparmex/

SosA, Georgina, "Democracia, cambio institucional y grupos de poder mediático en México: La 'Ley Televisa' (2005-2007) y la 
reforma electoral (2006-2008)", tesis de doctorado en Ciencias Políticas y Sociales, campo disciplinario en Sociología, Programa de Posgrado en Ciencias Políticas y Sociales, Universidad Nacional Autónoma de México, 3 de noviembre de 2014.

Tirado, Ricardo, "El poder en la Confederación de Cámaras Industriales", en C. Puga y M. Luna (coords.), Acción colectiva y organización. Estudios sobre desempeño asociativo, México, IIS-UNAM, 2008, pp. 93-142.

Tirado, Ricardo y Matilde Luna, "La politización de los empresarios mexicanos (1970-1982)", en Julio Labastida: Grupos económicos y organizaciones empresariales en México, México, Alianza Editorial Mexicana-UnAm, 1986, pp. 411-455.

Trejo García, Adrián, "Quieren empresarios reforma fiscal en serio", El Financiero, 5 de noviembre de 2013.

"Un balance de cara a la transmisión de poderes en el Ejecutivo", Consejo Coordinador Empresarial, 25 de noviembre de 2018, https:/ / www.cce.org.mx/un-balance-de-cara-a-la-transmisionde-poderes-en-el-ejecutivo/ (consulta del 9 de junio de 2019). "Vamos México, sin control", Proceso, 25 de mayo de 2003.

Zapata Novoa, Juan, Tercos y triunfadores de Monterrey; los retos de Monterrey en el siglo xx, Monterrey, Castillo, 1993.

ZermeÑo, Rubén, "Cotemar, empresa consentida y polémica", $R e-$ porte Índigo, 12 de julio de 2018. 
